\title{
Allocation Rules and the Stability of Mass Tort Class Actions
}

Joshua C. Teitelbaum

Georgetown University Law Center, jct48@law.georgetown.edu

This paper can be downloaded free of charge from:

https://scholarship.law.georgetown.edu/facpub/1068

https://ssrn-com.proxygt-law.wrlc.org/abstract=1241018

This open-access article is brought to you by the Georgetown Law Library. Posted with permission of the author. Follow this and additional works at: https://scholarship.law.georgetown.edu/facpub

Part of the Litigation Commons, and the Torts Commons 


\title{
Allocation Rules and the Stability of Mass Tort Class Actions
}

\author{
Joshua C. Teitelbaum* \\ Georgetown University
}

July 2, 2018

\begin{abstract}
This paper studies the effects of allocation rules on the stability of mass tort class actions. I analyze a two-stage model in which a defendant faces multiple plaintiffs with heterogeneous damage claims. In stage 1 , the plaintiffs play a noncooperative coalition formation game. In stage 2 , the class action and any individual actions by opt-out plaintiffs are litigated or settled. I examine how the method for allocating the class recovery interacts with other factors - the shape of the damage claims distribution, the scale benefits of the class action, and the plaintiffs' probability of prevailing at trial and bargaining power in settlement negotiations - to determine the asymptotic stability of the global class. My results suggest criteria to attorneys and courts for structuring and approving efficient allocations plans in mass tort class actions and for evaluating the requirements for class certification in mass tort cases. (JEL C72, K41)
\end{abstract}

*Joshua C. Teitelbaum, Georgetown University, 600 New Jersey Avenue NW, Washington, DC 20001, USA (jct48@georgetown.edu). For helpful comments and feedback, I wish to thank Talia Bar, Ani Guerdjikova, Lewis Kornhauser, Henrik Lando, and Charles Silver; workshop participants at Boston College, Case Western Reserve University, Drexel University, Florida State University, George Mason University, Georgetown University, Northwestern University, Roger Williams University, University at Buffalo, University of Illinois, University of Iowa, and the University of Virginia; and conference participants at the Annual Conference of the European Association of Law and Economics and the Annual Meeting of the American Law and Economics Association. 


\section{Introduction}

A class action allows one or more representative parties to sue or be sued on behalf of a class of similarly situated persons. Rule 23(b)(3) of the United States Federal Rules of Civil Procedure permits a case to proceed as a class action when, inter alia, "a class action is superior to other available methods for fairly and efficiently adjudicating the controversy" (Fed. R. Civ. P. 23(b)(3)). In light of the general tradeoff between equity and efficiency in matters of public policy and law (Okun, 1975; Kaplow \& Shavell, 2002), a class action that satisfies the requirements of Rule 23(b)(3) would appear to be socially desirable.

A distinguishing feature of a Rule 23(b)(3) class action is that the putative class members have the right to opt out of the class action and pursue their own interests (Fed. R. Civ. P. 23(c)(2)(B)). Advocates of opt-out rights offer various deontological and instrumental arguments in their favor. ${ }^{1}$ Notwithstanding the merits of these arguments, the right to opt out of a Rule 23(b)(3) class action creates the risk that the class will unravel in spite of the fact that a class action is in society's best interests. This risk is acknowledged widely among class action scholars (e.g., Abraham, 1987; Mullenix, 1991; Perino, 1997; Rosenberg, 2002; Campos, 2012), including by opt-out rights advocates (e.g., Schuck, 1995; Rutherglen, 1996; Nagareda, 2003; Williams, 2015).

The risk that the class will unravel is thought to be particularly significant in the case of a Rule 23(b)(3) mass tort class action (Coffee, 1987; Bone, 2003). Indeed, there is evidence that opt-out rates are highest in mass tort cases (Eisenberg \& Miller, 2004). A well-known example is the FenPhen class action, "the unraveling of [which] was caused by multiple opportunities to opt out of the settlement" (Campos, 2012, p. 1082). ${ }^{2}$ In recognition of this problem, several legal commentators propose restricting or even abolishing opt-out rights in mass tort class actions (e.g., Mullenix, 1986; Coffee, 1987; Rosenberg, 2003). Contrary to such proposals, however, Rule 23 continues to afford robust opt-out rights to members of a Rule 23(b)(3) class action.

A key reason why the class might unravel in a Rule 23(b)(3) mass tort class action is adverse selection due to damage averaging (Coffee, 1987; Bone, 2003). Damaging averaging occurs when the allocation rule governing the division of the net recovery of the class among its members assigns class members with below-average (above-average) claims more (less) than their pro rata shares. If the governing allocation rule engages in damage averaging, then, even if the per member expected recovery in the class action exceeds the mean expected recovery from separate actions (which may be the case if, for example, the class action enjoys economies of scale, superior prospects of prevailing at trial, or enhanced bargaining power in settlement negotiations), the amount that one or more putative class members with above-average claims can expect to recover by opting out may exceed the amount that they can expect to recover by remaining in the class action.

\footnotetext{
${ }^{1}$ The deontological arguments usually emphasize the concept of plaintiff autonomy and invoke the notion that "everyone should have his own day in court" (Ortiz v. Fireboard Corp., 527 U.S. 815, 846 (1999)). The instrumental arguments usually emphasize the idea that the right to opt out serves as a mechanism to mitigate the principal-agent problems inherent in class actions.

${ }^{2}$ Other examples of high profile mass tort class actions incude the Agent Organge, BP Deepwater Horizon, Dalkon Shield, Exxon Valdez, aebestos, breast implants, heart valve, HIV-contaminated blood, and tobacco litigations.
} 
This paper examines how different allocation rules influence the risk that the class will unravel in a Rule 23(b)(3) mass tort class action. I focus on three allocation rules: (1) equal sharing; (2) pro rata by damage claims; and (3) pro rata by outside options (i.e., by expected claim values). I consider these rules for two reasons. First and foremost, they run the gamut of damage averaging. Rules 1 and 3 correspond to full damage averaging and no damage averaging, respectively, while rule 2 involves partial damage averaging. ${ }^{3}$ Second, these rules are natural and obvious candidates for "fair" allocation rules; as one commentator states in a closely related context, each rule has "immediate, though perhaps naive, appeal" (Kornhauser, 1998, p. 1568).

I analyze a two-stage model of class action formation in which a single defendant faces multiple plaintiffs with heterogeneous damage claims. A global class action is certified at the outset. In stage 1 , the plaintiffs play a coalition formation game in which each plaintiff simultaneously announces whether it will remain in the class or opt out. Stage 1 is modeled as a noncooperative game in partition function form (e.g., Bloch, 2003; Yi, 2003). The global class is stable if the strategy profile in which all plaintiffs remain in the class constitutes a pure strategy Nash equilibrium. In stage 2 , the class action and any individual actions by opt-out plaintiffs are resolved via litigation or settlement. Stage 2 is modeled in the divergent expectations tradition (e.g., Priest \& Klein, 1984).

I examine the asymptotic stability of the global class under each allocation rule. The global class is asymptotically stable if the probability that it is stable converges to one as the number of plaintiffs becomes arbitrarily large. I am interested in the asymptotic stability of the global class because in the situation under consideration - a Rule 23(b)(3) mass tort class action - the number of plaintiffs presumably is large. This presumption follows not only from the fact that it is a mass tort class action, but also because certification under Rule 23(b)(3) implies that the class is "numerous" (Fed. R. Civ. P. 23(a)(1)).

I show that the global class is asymptotically stable if the net recovery of the class will be allocated pro rata in accordance with its members' outside options (rule 3), but that it may not be asymptotically stable if the net recovery of the class will be shared equally (rule 1) or allocated pro rata in accordance with the members' damage claims (rule 2). For rules 1 and 2, I derive necessary and sufficient conditions for the asymptotic stability of the global class. I also derive sufficient conditions for the asymptotic stability and instability of the global class under rules 1 and 2 . In addition, I show that the asymptotic stability of the global class under rule 1 necessarily implies the asymptotic stability of the global class under rule 2 but not vice versa.

I find that a key determinant of the asymptotic stability of the global class under rule 1 is the shape of the distribution of the plaintiffs' damage claims. Generally speaking, the global class is more likely to be asymptotically stable under rule 1 if the expected damage claim is high and the range of damage claims is narrow. If the claims distribution is unimodal and has a bounded

\footnotetext{
${ }^{3}$ Rule 2 involves partial damage averaging in my model because plaintiffs share a common probability of prevailing at trial. It also would involve partial damage averaging if the probability of prevailing at trial were higher for plaintiffs with above-average claims than for plaintiffs with below-average claims. However, if the probability of prevailing at trial were lower for plaintiffs with above-average claims than for plaintiffs with below-average claims, then rule 2 would involve negative averaging whereby class members with below-average (above-average) claims would receive less (more) than their pro rata shares.
} 
support, this implies that the global class is more likely to be asymptotically stable under rule 1 when the distribution is negatively skewed. In addition, I find that the magnitude of the scale benefits of the class action and the plaintiffs' probability of prevailing at trial and bargaining power in settlement negotiations are important determinants of the asymptotic stability of the global class under rules 1 and 2. In particular, if the scale benefits of a class action are high, the global class is more likely to be asymptotically stable under rules 1 and 2 if the plaintiffs' bargaining power in settlement negotiations is low. If, however, the scale benefits of a class action are low, the global class is less likely to be asymptotically stable under rules 1 and 2 if the plaintiffs' probability of prevailing at trial is high or their bargaining power in settlement negotiations is low.

My results demonstrate that selecting an allocation rule in a Rule 23(b)(3) mass tort class action generally involves a tradeoff between ex ante and ex post efficiency. On the one hand, the risk that the class will unravel due to adverse selection generally increases with the degree of damage averaging in which the governing allocation rule engages. On the other hand, the cost of implementing an allocation rule generally decreases as the degree of damage averaging in which it engages increases (Coffee, 1987, 1998; Silver \& Baker, 1998; Silver, 2000; Kishinevsky, 2017).

More importantly, my results suggest when this tradeoff may be avoided - e.g., when a class action achieves large economies of scale and the plaintiffs have negatively skewed damage claims over a narrow range and low bargaining power in settlement negotiations. In other words, my results provide guidance regarding when and how allocation rules may be used to promote the stability of the class in a Rule 23(b)(3) mass tort class action. As a consequence, they also suggest criteria for evaluating the requirements for class certification of mass tort cases and for approving settlements of mass tort class actions. I elaborate these points in my concluding discussion.

The remainder of the paper is organized as follows. Section 2 discusses the institutional background and related literature. Section 3 presents the model. Section 4 analyzes the asymptotic stability of the global class under each allocation rule. Section 5 illustrates the stability analysis with numerical examples. Section 6 offers concluding remarks. It discusses the implications of the analysis and possible extensions of the model. Appendix A contains certain mathematical details. Appendix B collects the proofs of all theorems.

\section{Institutional Background and Related Literature}

\subsection{Introduction to Class Actions and Rule 23}

The class action is a procedural device pursuant to which "[o]ne or more members of a class may sue or be sued as representative parties on behalf of all members" (Fed. R. Civ. P. 23(a)). In general, the resolution of a class action binds all members of the class, including absent parties. Thus, the class action forms an exception to the "principle of general application in Anglo-American

\footnotetext{
${ }^{4}$ As Silver (2000, p. 226) explains, "[i]t is more expensive to pay claimants amounts that roughly reflect the size and strength of their claims than it is to engage in damages averaging and pay them equal amounts, and it is more expensive still to distribute payments that reflect fine differences between claimants."
} 
jurisprudence that one is not bound by a judgment . . . in a litigation in which he is not designated as a party or to which he has not been made a party by service of process" (Ortiz v. Fireboard Corp., 527 U.S. 815, 846 (1999)).

The raison d'être of the class action is efficiency. Class actions can enhance efficiency in several ways. A class action can solve a collective action problem in a case in which individual actions are not economically viable, thereby promoting optimal deterrence (Amchem Products, Inc. v. Windsor, 521 U.S. 591, 617 (1997); Macey \& Miller 1991). When individual actions are economically viable, a class action can achieve economies of scale, thereby reducing litigation costs and promoting optimal investment in the litigation (Hay \& Rosenberg, 2000), and promote uniformity in the law, thereby avoiding the social costs associated with legal inconsistency.

The historical roots of the class action run deep. Litigation by representatives of a group seeking to redress communal harms dates back medieval England (Yeazell, 1987). The modern ancestry of the class action includes the bill of peace with multiple parties, which was developed in the seventeenth century by the Court of Chancery in England (Chafee, 1932, 1950). In the United States, the first provision for class actions in federal courts, Rule 48 of the Federal Equity Rules, was adopted in 1843. It permitted a representative suit when the parties on either side were too numerous to be brought before the court without manifest inconvenience and oppressive delays and the representative parties were sufficient to represent the interests of the absent parties (42 U.S. (1 How.) lvi (1843)). In 1912, Rule 48 was amended and restated as Rule 38. The revised rule succinctly provided, "When the question is one of common or general interest to many persons constituting a class so numerous as to make it impracticable to bring them all before the court, one or more may sue or defend for the whole" (226 U.S. 659 (1912)).

The existing class action device in the United States is Rule 23 of the Federal Rules of Civil Procedure. Originally adopted in 1938, Rule 23 was substantially revised in 1966 and last amended in 2009. In April 2018, the Supreme Court adopted new amendments to Rule 23 that take effect December 1, 2018 (if not disapproved by Congress). In what follows, I assume that Rule 23 incorporates the pending 2018 amendments.

As amended, Rule 23(a) enumerates four prerequisites to a class action: "(1) the class is so numerous that joinder of all members is impracticable; (2) there are questions of law or fact common to the class; (3) the claims or defenses of the representative parties are typical of the claims or defenses of the class; and (4) the representative parties will fairly and adequately protect the interests of the class." Commonly known as numerosity, commonality, typicality, and adequacy of representation (Amchem Products, Inc. v. Windsor, 521 U.S. 591, 613 (1997)), these prerequisites echo the requirements of the former equity rules (Hensler et al., 2000).

Rule 23(b) specifies three situations in which a case that satisfies the prerequisites of Rule 23(a) may proceed as a class action. Rule 23(b)(1) permits a class action when separate actions would create a risk that the party opposing the class would face inconsistent or varying adjudications or that an adjudication as to one or more class members would prejudice the interests of other class members. For example, Rule 23(b)(1) traditionally includes "limited fund" cases (Ortiz v. 
Fireboard Corp., 527 U.S. 815, 834 (1999)), in which "claims are made by numerous persons against a fund insufficient to satisfy all claims" (Advisory Committee's Notes to Rule 23). Rule 23(b)(2) covers situations where the actions or omissions of the party opposing the class affect the entire class and injunctive or declaratory relief respecting the class as a whole is appropriate. A prime example is a civil rights suit alleging unlawful discrimination against a class (Advisory Committee's Notes to Rule 23; Amchem Products, Inc. v. Windsor, 521 U.S. 591, 614 (1997); Miller 1979).

Rule 23(b)(3) provides that a class action may be maintained if common questions of law or fact predominate over individual questions and if a class action is "superior to other available methods for fairly and efficiently adjudicating the controversy." According to its drafters, Rule 23(b)(3) "encompasses those cases in which a class action would achieve economies of time, effort, and expense, and promote uniformity of decision as to persons similarly situated, without sacrificing procedural fairness or bringing about other undesirable results" (Advisory Committee's Notes to Rule 23). Rule 23(b)(3) is a catchall for class actions that do not fit into the "pigeonholes" of Rule 23(b)(1) or (2) (Bronsteen \& Fiss, 2003, p. 1434), but that "may nevertheless be convenient and desirable depending upon the particular facts" (Advisory Committee's Notes to Rule 23).

Class actions maintained under Rule 23(b)(1) and Rule 23(b)(2) are mandatory; class members do not have a statutory right to exclude themselves from the class. By contrast, putative class members have the right to opt out of a Rule 23(b)(3) class action. The rules require the court to exclude from the class any member who requests exclusion in accordance with the time and manner restrictions set forth in the class action notice (Fed. R. Civ. P. 23(c)(2)(B)(v)-(vi)). Those who duly opt out are not bound by the outcome of the class action (Fed. R. Civ. P. 23(c)(3)). When deemed appropriate by the court, a class may be divided into subclasses that are each treated as a separate class (Fed. R. Civ. P. 23(c)(5)). In addition, a class action may be brought or maintained with respect to particular issues only (Fed. R. Civ. P. 23(c)(4)).

Any settlement of a certified class action must be approved by the court (Fed. R. Civ. P. 23(e)). In order for the settlement to be binding, the court must find that the settlement is "fair, reasonable, and adequate" (Fed. R. Civ. P. 23(e)(2)). In making this finding, the court must consider, inter alia, whether "the relief provided for the class is adequate, taking into account . . the effectiveness of any proposed method of distributing relief to the class, including the method of processing classmember claims" (Fed. R. Civ. P. 23(e)(2)(c)(ii)), and whether the settlement "treats class members equitably relative to each other" (Fed. R. Civ. P. 23(e)(2)(D)). The court's review of a settlement is distinct from and in addition to the court's certification inquiry, including with respect to the adequacy requirement and, in the case of a Rule 23(b)(3) class action, the superiority requirement (Amchem Products, Inc. v. Windsor, 521 U.S. 591, 619-22 (1997); Nagareda 2002). If the class action was previously certified under Rule 23(b)(3), the court may refuse to approve a settlement unless it affords class members a new opportunity to opt out (Fed. R. Civ. P. 23(e)(4)).

When class actions are certified in mass tort cases, they usually are certified under Rule 23(b)(3) (Weinstein, 1995). The use of class actions to resolve mass tort cases, however, is controversial (Schuck, 1995; Hensler, 2001). Moreover, judicial attitudes towards mass tort class actions have 
ebbed and flowed since the 1966 overhaul of Rule 23 (Coffee, 1995; Perino, 1997; Klonoff, 2013, 2017). ${ }^{5}$ Still, mass tort class actions remain relevant today (Klonoff, 2017; Miller, 2018).

\subsection{Relation to the Literature}

This paper relates to several strands of literature within law, economics, and their intersection. Within law, this paper contributes to the vast literature on class actions. In particular, it adds to the legal scholarship that discusses allocations in class actions, including Morawetz (1993), Baker \& Silver (1997), Coffee (1998), Silver \& Baker (1998), Dana (2006), Edelman, Nagareda, \& Silver (2006), Macey \& Miller (2009), Rave (2013), Kishinevsky (2017), and Ratner (2017).

This paper closely relates and directly contributes to the small literature on the economics of class actions. This literature includes Kornhauser (1983, 1998), Che (1996), Perino (1997), Marceau \& Mongrain (2003), and Deffains \& Langlais (2011, 2012).

Kornhauser $(1983,1998)$ and Perino (1997) model the formation of a class action as a cooperative game in characteristic function form. Kornhauser considers an "allocation of common costs" game and adopts the core of the game as the standard for a "fair" allocation. While certain of his results are comparable to the results in this paper, Kornhauser focuses on how different court procedures for approving settlements (intervention rules, voting rules, and attorney compensation schemes) influence whether the class attorney and the defendant will propose a fair allocation. Perino uses a simple, three-player game to construct a series of examples that illustrate how the concept of core stability can elucidate several academic theories and real-world phenomena pertaining to class actions and opt-out rights. Although he does not develop a general model, Perino demonstrates the usefulness of core theory for the analysis of class action dynamics.

Che (1996), Marceau \& Mongrain (2003), and Deffains \& Langlais (2011, 2012) study the equilibrium formation of class actions using different noncooperative games. Che examines the adverse selection hypothesis in a model that features a single defendant, two types of plaintiffs (small stakes and large stakes), and full damaging averaging. He focuses on the role of asymmetric information, considering two cases: when the defendant has complete information about the plaintiffs' claims and when the plaintiffs' claims are private information. In both cases he finds equilibria in which the class partially or fully unravels, although he finds that pure adverse selection arises only in the case of complete information. Che's model is closely related to my model and his results in the case complete information are comparable to my results on class stability under equal sharing. Marceau \& Mongrain analyze a waiting game among multiple plaintiffs with heterogenous damage claims and examine how the degree of damage averaging influences which plaintiff will assume the role of class representative and initiate the class action. They find that if there is full damage averaging,

\footnotetext{
${ }^{5}$ The advisory committee's notes accompanying the 1966 amendments to Rule 23 state that a "'mass accident' resulting in injuries to numerous persons is ordinarily not appropriate for a class action because of the likelihood that significant questions, not only of damages but of liability and defenses to liability, would be present, affecting the individuals in different ways" (Advisory Committee's Notes to Rule 23). However, courts often disregard this comment (Kane, 2018, sec. 1783) and ocassionally expressly repudiate it (e.g., In re A.H. Robins Co., Inc., 880 F.2d 709, 729-38 (4th Cir. 1989)).
} 
the class representative will be the plaintiff with the lowest damage claim, while if there is less than full damage averaging, other plaintiffs may initiate the class action. Deffains \& Langlais consider a sequential entry game between two plaintiffs (high stakes and low stakes) that have been injured by the same defendant. They focus on the consequences of information externalities and information sharing for the formation of a class action, though in an extension of their model they prove one result on damage averaging that is comparable to results in this paper.

In addition, this paper draws on the litigation and settlement literature within law and economics, including, most notably, Landes (1971), Posner (1973), Gould (1973), Shavell (1982), Priest \& Klein (1984), and Hylton (2006). This paper also draws on the literature within economics and game theory on noncooperative games of coalition formation. Surveys of this literature are provided by Konishi, Le Breton, \& Weber (1997), Bloch (1997, 2003), and Yi (2003).

\section{Two-Stage Model of Class Action Formation}

Consider a mass tort case with $n$ plaintiffs and one defendant. Let $N$ denote the set of all plaintiffs and $i$ denote an arbitrary plaintiff in $N$. All parties are risk neutral expected wealth maximizers.

Each plaintiff $i \in N$ has a damage claim $\theta_{i}$ against the defendant. Each plaintiff's damage claim is its private knowledge. However, it is common knowledge that the plaintiffs' damage claims are independent and identically distributed according to a cumulative distribution function $F_{\theta}$ and a probability density function $f_{\theta}$ that is strictly positive on its support set $[\underline{\theta}, \bar{\theta}]$, where $0<\underline{\theta}<\bar{\theta}<\infty$. The defendant's assets are available and sufficient to satisfy the damage claims of all plaintiffs.

At the outset, a class action on behalf of all plaintiffs is certified under Rule 23(b)(3). In stage 1 , each plaintiff simultaneously announces whether it will remain in the class action or opt out pursuant to Rule 23(c). Assuming simultaneous announcements captures the idea that a plaintiff does not know the announcements of the other plaintiffs when it makes its announcement. Let $A \subseteq N$ denote the subset of plaintiffs that remain in the class action and let $N / A$ denote the subset of plaintiffs that opt out. I refer to $A$ as the class, to each plaintiff $i \in A$ as a class member, and to each plaintiff $i \in N \backslash A$ as an opt-out plaintiff. The number of class members is denoted by $|A|$ and I refer to $|A|$ as the class size.

I assume that each plaintiff's announcement is binding (i.e., no class member may opt out and no opt-out plaintiff may rejoin the class) and that each opt-out plaintiff must pursue its claim individually (e.g., no other class actions are maintained on behalf of opt-out plaintiffs and no optout plaintiffs maintain joinder actions under Rule 20). ${ }^{6}$ Accordingly, the plaintiffs' announcements

induce a partition $\Omega^{A}$ of $N$, where $\Omega^{A}=\left\{A,(i)_{i \in N \backslash A}\right\}$. I refer to $\Omega^{A}$ as the class structure and to each $\omega \in \Omega^{A}$ as a stage 2 plaintiff. For the sake of brevity, I often refer to a stage 2 plaintiff simply as a plaintiff.

\footnotetext{
${ }^{6}$ Rule 20 provides, in pertinent part: "All persons may join in one action as plaintiffs if they assert any right to relief jointly, severally, or in the alternative in respect of or arising out of the same transaction, occurrence, or series of transactions or occurrences and if any question of law or fact common to all these persons will arise in the action" (Fed. R. Civ. P. 20(a)).
} 
In stage 2 , the defendant and each plaintiff $\omega \in \Omega^{A}$ resolve their dispute via litigation or settlement. I assume that the class' damage claim equals the expected damage claim multiplied by the class size: $\theta_{A}=E[\theta] \cdot|A|$. In addition, I assume that there are no externalities or spillovers across plaintiffs. In particular, I assume that the class action and any individual actions by opt-out plaintiffs are resolved simultaneously and that all claims have the same priority in bankruptcy.

Because the plaintiffs' expected payoffs in stage 1 are functions of their expected recoveries in stage 2 , I proceed in reverse chronological order and begin with stage 2.

\subsection{Stage 2: Dispute Resolution}

Plaintiff $\omega$ and the defendant settle rather than litigate their dispute if a settlement range existsi.e., if plaintiff $\omega$ 's reservation price (its minimum settlement demand) is less than or equal to the defendant's reservation price (its maximum settlement offer):

$$
P_{\omega} \theta_{\omega}-C_{\omega} \leq Q_{\omega} \theta_{\omega}+K_{\omega}
$$

where (i) $P_{\omega}$ and $Q_{\omega}$ denote the respective estimates by plaintiff $\omega$ and the defendant of the probability that plaintiff $\omega$ would prevail at trial and (ii) $C_{\omega}>0$ and $K_{\omega}>0$ denote the respective litigation costs of plaintiff $\omega$ and the defendant. ${ }^{7}$ If no settlement range exists the parties litigate. Condition (1) implicitly assumes that if the parties litigate and plaintiff $\omega$ prevails at trial the defendant is liable to plaintiff $\omega$ for its damage claim $\theta_{\omega}$, that the parties bear their own litigation costs, ${ }^{8}$ and that settlement costs are zero. ${ }^{9}$ By (1), $Q_{\omega}>P_{\omega}$ is a sufficient (but not necessary) condition for settlement and $P_{\omega}>Q_{\omega}$ is a necessary (but not sufficient) condition for litigation.

The parties estimate the probability that plaintiff $\omega$ would prevail at trial with error. In particular, I assume that the parties' estimates are given by

$$
\begin{gathered}
P_{\omega}=W_{\omega}+\epsilon_{\omega} ; \\
Q_{\omega}=W_{\omega}+\mu_{\omega},
\end{gathered}
$$

where (i) $W_{\omega}$ is the probability that plaintiff $\omega$ would prevail at trial and (ii) $\epsilon_{\omega}$ and $\mu_{\omega}$ represent the respective prediction errors of plaintiff $\omega$ and the defendant. I assume that $\epsilon_{\omega}$ and $\mu_{\omega}$ are independently realized at the beginning of stage 2 and that each is uniformly distributed on the interval $\left[\max \left\{-W_{\omega}, W_{\omega}-1\right\}, \min \left\{W_{\omega}, 1-W_{\omega}\right\}\right]$. The latter assumption ensures that the parties' estimates of the probability that plaintiff $\omega$ would prevail at trial are between zero and one $\left(P_{\omega} \in\right.$ $[0,1]$ and $\left.Q_{\omega} \in[0,1]\right)$ and are correct in expectation $\left(E\left[P_{\omega}\right]=E\left[Q_{\omega}\right]=W_{\omega}\right)$. This assumption also implies that the variance of the parties' prediction errors is zero at $W_{\omega}=0$ and $W_{\omega}=1$, when

\footnotetext{
${ }^{7}$ Condition (1) is a so-called Landes-Posner-Gould condition (Landes, 1971; Posner, 1973; Gould, 1973).

${ }^{8}$ This reflects the American rule (see, e.g., Shavell, 1982; Hylton, 1993)

${ }^{9}$ This is a standard assumption in the literature (see, e.g., Shavell, 1982; Hylton, 1993, 2006). Alternatively, we could relax this assumption and then assume that litigation costs exceed settlement costs, in which case $C_{\omega}$ and $K_{\omega}$ would denote the excess of litigation costs over settlement costs for plaintiff $\omega$ and the defendant, respectively.
} 
the outcome of a trial is certain, and achieves its maximum at $W_{\omega}=\frac{1}{2}$, when the outcome of a trial is most uncertain (cf. Priest \& Klein, 1984; Hylton, 2006).

Given (2) and (3), we can restate condition (1) as follows: plaintiff $\omega$ and the defendant settle rather than litigate their dispute if

$$
\epsilon_{\omega}-\mu_{\omega} \leq \frac{C_{\omega}+K_{\omega}}{\theta_{\omega}}
$$

It follows that the probability that plaintiff $\omega$ and the defendant settle is

$$
\phi_{\omega}=F_{\Delta\left(W_{\omega}\right)}\left(\frac{C_{\omega}+K_{\omega}}{\theta_{\omega}}\right)
$$

where $F_{\Delta\left(W_{\omega}\right)}$ is the cumulative distribution function of $\Delta\left(W_{\omega}\right)=\epsilon_{\omega}-\mu_{\omega} \cdot{ }^{10}$ Conversely, the probability that plaintiff $\omega$ and the defendant litigate is $1-\phi_{\omega}$.

We can infer from (4) and (5) how various factors generate litigation in the model. Condition (4) implies that litigation may result from "overoptimism" on the part of both parties (i.e., $\epsilon_{\omega}>0$ and $\left.\mu_{\omega}<0\right)$ (cf. Shavell, 1982; Hylton, 2006). Equation (5) implies that the probability that the parties litigate is weakly decreasing in joint litigation costs, $C_{\omega}+K_{\omega}$, and weakly increasing in the litigation stakes, $\theta_{\omega}$ (cf. Posner, 1973; Hylton, 2006). This is because $F_{\Delta_{\omega}}$ is nondecreasing. In addition, equation (5) implies that the probability of litigation is weakly greater the more uncertain is the outcome of a trial (cf. Priest \& Klein, 1984; Hylton, 2006). This is because $F_{\Delta\left(W_{\omega}\right)}$ first-order stochastically dominates $F_{\Delta\left(W_{v}\right)}$ on $[0,1]$ if $\left|W_{\omega}-\frac{1}{2}\right|<\left|W_{v}-\frac{1}{2}\right|$.

\subsection{Stage 1: Class Formation Game}

The formation of the class is modeled as a noncooperative, simultaneous move, single coalition formation game $\Gamma$, where: (i) the set of players is the set of all plaintiffs, $N$; (ii) the set of actions available to each plaintiff is $\{$ In, Out $\}$; and (iii) payoffs are described by a per-member partition function $V=\mathcal{R} \circ \Pi$, where (a) $\Pi$ is a partition function that assigns to each class structure $\Omega^{A}$ a vector $\pi \in \mathbb{R}^{\left|\Omega^{A}\right|}$ which specifies the expected recovery $\pi_{\omega}$ of each plaintiff $\omega \in \Omega^{A}$ in stage 2 and (b) $\mathcal{R}$ is an allocation rule that maps each stage 2 expected recovery profile $\pi$ into a vector $v \in \mathbb{R}^{n}$ which specifies the expected payoff $v_{i}$ of each plaintiff $i \in N$ at stage 1 .

\subsubsection{Expected Recovery}

If the parties litigate, plaintiff $\omega$ expects to recover

$$
\pi_{\omega}^{L}=P_{\omega} \theta_{\omega}-C_{\omega}
$$

If the parties settle, plaintiff $\omega$ expects to recover its minimum settlement demand, $P_{\omega} \theta_{\omega}-C_{\omega}$, plus its bargained-for share of the joint surplus from settlement, $\Lambda_{\omega}=\left(Q_{\omega} \theta_{\omega}+K_{\omega}\right)-\left(P_{\omega} \theta_{\omega}-C_{\omega}\right)$.

\footnotetext{
${ }^{10}$ The distribution of $\Delta\left(W_{\omega}\right)$ is derived in appendix A.
} 
I assume plaintiff $\omega$ expects Nash bargaining over the surplus $\Lambda_{\omega}$. Accordingly, if $\lambda_{\omega} \in[0,1]$ represents plaintiff $\omega$ 's bargaining power, plaintiff $\omega$ expects to recover

$$
\begin{aligned}
\pi_{\omega}^{S} & =\left(P_{\omega} \theta_{\omega}-C_{\omega}\right)+\lambda_{\omega} \Lambda_{\omega} \\
& =\lambda_{\omega}\left(Q_{\omega} \theta_{\omega}+K_{\omega}\right)+\left(1-\lambda_{\omega}\right)\left(P_{\omega} \theta_{\omega}-C_{\omega}\right) .
\end{aligned}
$$

Hence, plaintiff $\omega$ 's expected recovery in stage 2 is

$$
\begin{aligned}
\pi_{\omega} & =\phi_{\omega} \pi_{\omega}^{S}+\left(1-\phi_{\omega}\right) \pi_{\omega}^{L} \\
& =\phi_{\omega} \lambda_{\omega}\left(Q_{\omega} \theta_{\omega}+K_{\omega}\right)+\left(1-\phi_{\omega} \lambda_{\omega}\right)\left(P_{\omega} \theta_{\omega}-C_{\omega}\right) .
\end{aligned}
$$

Of course, this assumes plaintiff $\omega$ has correct expectations with regard to its bargaining power $\lambda_{\omega}$ and the probability of settlement $\phi_{\omega}$. This seems reasonable insofar as the plaintiff (or its lawyer) has experience with or data on similar cases (cf. Priest \& Klein, 1984).

\subsubsection{Expected Payoffs}

Under any allocation rule, the expected payoff of each opt-out plaintiff $i \in N \backslash A$ under class structure $\Omega^{A}$ is simply the expected value at stage 1 of its expected recovery in stage 2 . However, the expected payoff of each class member $i \in A$ under class structure $\Omega^{A}$ depends on the allocation rule $\mathcal{R}$. I consider the following three allocation rules, each of which is defined in terms of the vector of expected payoffs $v$ it induces:

$\left(\mathcal{R}^{1}\right) \quad$ Equal sharing: $v_{i}\left(\Omega^{A}\right)=\left\{\begin{array}{ll}\frac{1}{|A|} E\left[\pi_{A}\right] & \text { for } i \in A \\ E\left[\pi_{i}\right] & \text { for } i \in N \backslash A\end{array}\right.$;

$\left(\mathcal{R}^{2}\right) \quad$ Pro rata by damage claims: $v_{i}\left(\Omega^{A}\right)=\left\{\begin{array}{ll}\frac{\theta_{i}}{\theta_{A}} E\left[\pi_{A}\right] & \text { for } i \in A \\ E\left[\pi_{i}\right] & \text { for } i \in N \backslash A\end{array} ;\right.$

$\left(\mathcal{R}^{3}\right) \quad$ Pro rata by outside options: $v_{i}\left(\Omega^{A}\right)=\left\{\begin{array}{ll}\frac{E\left[\pi_{i}\right]}{\sum_{j \in A} E\left[\pi_{j}\right]} E\left[\pi_{A}\right] & \text { for } i \in A \\ E\left[\pi_{i}\right] & \text { for } i \in N \backslash A\end{array}\right.$.

\subsubsection{Notion of Stability}

The class structure $\Omega^{A}$ is stable if, given the announcements of the other plaintiffs, no class member could increase its expected payoff by opting out of the class and no opt-out plaintiff could increase its expected payoff by remaining in the class. Formally, for a class member $i \in A$, let $\Omega_{-i}^{A}$ denote the alternative class structure in which plaintiff $i$ opts out of the class action, i.e., $\Omega_{-i}^{A}=\left\{A \backslash\{i\}, i,(j)_{j \in N \backslash A}\right\}$. I refer to $v_{i}\left(\Omega_{-i}^{A}\right)$ as class member $i$ 's outside option. Similarly, for an opt-out plaintiff $i \in N \backslash A$, let $\Omega_{+i}^{A}$ denote the alternative class structure in which plaintiff $i$ remains 
the class action, i.e., $\Omega_{+i}^{A}=\left\{A \cup\{i\},(j)_{j \in N \backslash A \cup\{i\}}\right\}$. I refer to $v_{i}\left(\Omega_{+i}^{A}\right)$ as opt-out plaintiff $i$ 's inside option. The class structure $\Omega^{A}$ is internally stable if for each class member $i \in A$ its expected payoff under $\Omega^{A}$ is greater than its outside option:

$$
v_{i}\left(\Omega^{A}\right) \geq v_{i}\left(\Omega_{-i}^{A}\right) \text { for all } i \in A
$$

The class structure $\Omega^{A}$ is externally stable if for each opt-out plaintiff $i \in N \backslash A$ its expected payoff under $\Omega^{A}$ is greater than or equal to its inside option:

$$
v_{i}\left(\Omega^{A}\right) \geq v_{i}\left(\Omega_{+i}^{A}\right) \text { for all } i \in N \backslash A .
$$

The class structure $\Omega^{A}$ is stable if it is both internally stable and externally stable. Note that this notion of stability corresponds to the concept of pure strategy Nash equilibrium: the class structure $\Omega^{A}$ is stable if and only if the announcement profile that induces $\Omega^{A}$ constitutes a pure strategy Nash equilibrium of game $\Gamma$. This notion of stability was introduced by d'Aspremont et al. (1983). My formulation closely follows Weikard (2009).

For purposes of this paper, I focus on the stability of the class structure $\Omega^{N}$, which consists of the class of all plaintiffs, $A=N$, and no opt-out plaintiffs. I refer to $\Omega^{N}$ as the global class. Note that the global class is stable provided it is internally stable; it is trivially externally stable because there are no opt-out plaintiffs. I focus on the global class for two reasons. First, it is the default class structure. The global class is formed by operation of law upon certification of a class action under Rule 23. Second, it presumably is the efficient class structure. Class certification under Rule 23(b)(3) on behalf of all plaintiffs implies that "a class action is superior to other available methods for fairly and efficiently adjudicating the controversy" (Fed. R. Civ. P. 23(b)(3)) and that it is inappropriate to divide the global class into subclasses (Fed. R. Civ. P. 23(c)(5)).

In particular, I examine the asymptotic stability of the global class.

Definition 1 The global class is asymptotically stable if and only if for every plaintiff $i \in N$, $\operatorname{plim}_{n \rightarrow \infty}\left(v_{i}\left(\Omega^{N}\right)-v_{i}\left(\Omega_{-i}^{N}\right)\right) \geq 0$.

According to definition 1, the global class is asymptotically stable if and only if the probability that it is (internally) stable converges to one as the number of plaintiffs becomes arbitrarily large. ${ }^{11}$ As noted above, I examine the asymptotic stability of the global class because the situation under consideration is a mass tort class action in which the class is "numerous" (Fed. R. Civ. P. 23(a)(1)).

\subsubsection{Additional Assumptions}

Symmetry. On the basis that class certification under Rule 23(b)(3) implies that the plaintiffs are "similarly situated" with respect to their factual and legal claims against the defendant (Advisory

\footnotetext{
${ }^{11}$ To see this, note that $\operatorname{plim}_{n \rightarrow \infty}\left(v_{i}\left(\Omega^{A}\right)-v_{i}\left(\Omega_{-i}^{A}\right)\right)=d \geq 0$ if and only if for all $e>0$, $\lim _{n \rightarrow \infty} \operatorname{Pr}\left(\left|\left(v_{i}\left(\Omega^{A}\right)-v_{i}\left(\Omega_{-i}^{A}\right)\right)-d\right| \stackrel{<}{<}\right)=1$
} 
Committee's Notes to Rule 23), I assume that: (i) each individual plaintiff has the same litigation costs and the defendant's litigation costs are the same with respect to each individual plaintiff:

$$
\begin{aligned}
& C_{\omega}=C \text { and } K_{\omega}=K \text { for all } \omega \neq A ; \\
& C_{A}=C \text { and } K_{A}=K \text { for }|A|=1 ;
\end{aligned}
$$

(ii) each plaintiff has the same probability that it would prevail at trial:

$$
W_{\omega}=W \text { for all } \omega \in \Omega^{A}
$$

and (iii) each plaintiff has the same bargaining power in settlement negotiations:

$$
\lambda_{w}=\lambda \text { for all } \omega \in \Omega^{A} .
$$

Economies of scale. Class certification under Rule 23(b)(3) also implies that "a class action would achieve economies of time, effort, and expense" (Advisory Committee's Notes to Rule 23). Accordingly, I assume that although litigation costs are increasing in class size, per-plaintiff litigation costs are weakly decreasing in class size, but always positive:

$$
\begin{gathered}
C_{A} \geq C \text { and } K_{A} \geq K \text { for }|A|>1 ; \\
\frac{1}{|A|} C_{A} \leq \frac{1}{\left|A^{\prime}\right|} C_{A^{\prime}} \text { and } \frac{1}{|A|} K_{A} \leq \frac{1}{\left|A^{\prime}\right|} K_{A^{\prime}} \text { for all } A, A^{\prime} \subseteq N,|A|>\left|A^{\prime}\right| ; \\
\frac{1}{|A|} C_{A} \rightarrow c>0 \text { and } \frac{1}{|A|} K_{A} \rightarrow k>0 \text { as }|A| \rightarrow \infty .
\end{gathered}
$$

Because the class enjoys neither a higher probability of prevailing at trial nor enhanced bargaining power in settlement negotiations, these scale benefits provide the key incentive in the model for plaintiffs to remain in the class action. Indeed, the per-plaintiff net recovery is weakly increasing in class size and achieves its maximum when the class includes all plaintiffs (i.e., when $A=N$ ).

Viability of litigation. I restrict attention to mass tort cases in which litigation is objectively viable for each plaintiff:

$$
W \underline{\theta}-C \geq 0 .
$$

Accordingly, the model does not pertain to mass torts for which a class action is socially desirable because it solves a collective action problem. Rather, it pertains to mass torts for which a class action is socially desirable because it achieves economies of scale. Similarly, I assume that litigation against each plaintiff is objectively viable for the defendant:

$$
W \underline{\theta}-K \geq 0 .
$$




\section{Asymptotic Stability of the Global Class}

This section examines the asymptotic stability of the global class under each allocation rule. I show that the global class is asymptotically stable if the net recovery of the class is allocated pro rata in accordance with the members' outside options $\left(\mathcal{R}^{3}\right)$, but that the global class is not necessarily asymptotically stable if the net recovery of the class is shared equally by the members $\left(\mathcal{R}^{1}\right)$ or allocated pro rata in accordance with their damage claims $\left(\mathcal{R}^{2}\right)$. For $\mathcal{R}^{1}$ and $\mathcal{R}^{2}$, I derive necessary and sufficient conditions for the asymptotic stability of the global class as well as sufficient conditions for the asymptotic stability and instability of the global class. In addition, I show that the asymptotic stability of the global class under $\mathcal{R}^{1}$ necessarily implies the asymptotic stability of the global class under and $\mathcal{R}^{2}$ but not vice versa.

Before proceeding with the analysis by allocation rule, I note the following prefatory results, which hold for every allocation rule.

Lemma 1 Take any allocation rule.

(a) Take any $A \subset N$. Then for all $i \in N \backslash A, \phi_{i} \leq \phi_{A}$ if and only if $\theta_{i}>\left(\frac{C+K}{\frac{1}{|A|}\left(C_{A}+K_{A}\right)}\right)\left(\frac{1}{|A|} \theta_{A}\right)$.

(b) Define $\theta_{(1)}=\min _{1 \leq i \leq n} \theta_{i}$ and $\phi_{(1)}=F_{\Delta(W)}\left(\frac{C+K}{\theta_{(1)}}\right)$. Then $\phi_{(1)} \geq \phi_{N}$.

(c) Define $\theta_{(n)}=\max _{1 \leq i \leq n} \theta_{i}$ and $\phi_{(n)}=F_{\Delta(W)}\left(\frac{C+K}{\theta_{(n)}}\right)$. Then:

(i) $\operatorname{plim}_{n \rightarrow \infty} \theta_{(n)}=\bar{\theta}$;

(ii) $\operatorname{plim}_{n \rightarrow \infty}\left(\phi_{(n)}-\phi_{N}\right) \leq 0$ if $\bar{\theta}>\left(\frac{C+K}{c+k}\right) E[\theta]$; and

(iii) $\operatorname{plim}_{n \rightarrow \infty}\left(\phi_{(n)}-\phi_{N}\right) \geq 0$ if $\bar{\theta}<\left(\frac{C+K}{c+k}\right) E[\theta]$.

Lemma 1(a) says that an opt-out plaintiff is less likely to settle, and therefore more likely to litigate, than the class if and only if its damage claim exceeds the average damage claim of the class members by a factor greater than the scale benefit of the class action. Lemma 1(b) says that the member of the global class with the lowest damage claim would be more likely to settle, and therefore less likely to litigate, than the global class were that member to opt out. Lemma 1(c)(i) says that, as the number of plaintiffs becomes arbitrarily large, the probability that at least one plaintiff has the maximum damage claim converges to one. Lemmas 1(c)(ii) and (iii) say that, as the number of plaintiffs becomes arbitrarily large, the probability that the member of the global class with the highest damage claim would be less (more) likely to settle, and therefore more (less) likely to litigate, than the global class were that member to opt out converges to one, provided that the factor by which the maximum damage claim exceeds the expected damage claim is greater (less) than the maximum scale benefit of a class action. 


\subsection{Equal Sharing $\left(\mathcal{R}^{1}\right)$}

The following proposition sets forth a necessary and sufficient condition for the asymptotic stability of the global class under equal sharing.

Proposition 1 Suppose the allocation rule is $\mathcal{R}^{1}$. Then the global class is asymptotically stable if and only if

$$
\bar{\theta} \leq E[\theta]+\xi_{1},
$$

where $\xi_{1}=\frac{1}{W}\left((C-c)+\lambda\left[F_{\Delta(W)}\left(\frac{c+k}{E[\theta]}\right)(c+k)-F_{\Delta(W)}\left(\frac{C+K}{\bar{\theta}}\right)(C+K)\right]\right)$.

The following results follow from proposition 1.

Corollary 1 Suppose the allocation rule is $\mathcal{R}^{1}$. Then:

(a) The global class is not asymptotically stable if $E[\theta]<\bar{\theta}-\underline{\theta}$.

(b) If $E[\theta]>\bar{\theta}-\underline{\theta}$, then:

(i) the global class is asymptotically stable if $\frac{C+K}{c+k}$ is sufficiently high and $\lambda$ is sufficiently low; and

(ii) the global class is not asymptotically stable if $\frac{C+K}{c+k}$ is sufficiently low and either $W$ is sufficiently high or $\lambda$ is sufficiently low.

Corollary 1(a) implies that a key determinant of the asymptotic stability of the global class under $\mathcal{R}^{1}$ is the shape of the distribution of the plaintiffs' damage claims. It suggests that the global class is more likely to be asymptotically stable under $\mathcal{R}^{1}$ if the expected damage claim is high and the range of damage claims is narrow. If the distribution of the plaintiffs' damage claims is unimodal, corollary 1(a) implies that the global class is more likely to be asymptotically stable under $\mathcal{R}^{1}$ if the distribution is negatively skewed. Corollary 1 (b) suggests that the global class is more likely to be asymptotically stable under $\mathcal{R}^{1}$ if the scale benefits of a class action are high and the plaintiffs' bargaining power in settlement negotiations is low. If the scale benefits of a class action are low, however, corollary 1(b) suggests that the global class is less likely to be asymptotically stable under $\mathcal{R}^{1}$ if the plaintiffs' probability of prevailing at trial is high or their bargaining power in settlement negotiations is low.

\subsection{Pro Rata by Damage Claims $\left(\mathcal{R}^{2}\right)$}

The following proposition sets forth a necessary and sufficient condition for the asymptotic stability of the global class if the net recovery of the class is allocated pro rata in accordance with the members' damage claims. 
Proposition 2 Suppose the allocation rule is $\mathcal{R}^{2}$. Then the global class is asymptotically stable if and only if

$$
\bar{\theta} \leq \frac{C}{c} E[\theta]+\xi_{2}
$$

where $\xi_{2}=\frac{\lambda}{c}\left[\bar{\theta} F_{\Delta(W)}\left(\frac{c+k}{E[\theta]}\right)(c+k)-E[\theta] F_{\Delta(W)}\left(\frac{C+K}{\bar{\theta}}\right)(C+K)\right]$.

The following results follow from proposition 2 .

Corollary 2 Suppose the allocation rule is $\mathcal{R}^{2}$. Then:

(a) The global class is asymptotically stable if $\frac{C+K}{c+k}$ is sufficiently high and $\lambda$ is sufficiently low; in particular, if $\frac{C+K}{c+k}>\frac{\bar{\theta}}{E[\theta]}$ and $\lambda \leq \frac{c \bar{\theta}-C E[\theta]}{\bar{\theta} F_{\Delta(W)}\left(\frac{c+k}{E[\theta]}\right)(c+k)-E[\theta] F_{\Delta(W)}\left(\frac{C+K}{\bar{\theta}}\right)(C+K)}$.

(b) The global class is asymptotically stable if $\left(\frac{\bar{\theta}}{E[\theta]}-\frac{K}{c}\right)\left(1+\frac{k}{c}\right)^{-1} \leq \frac{C+K}{c+k} \leq \frac{\bar{\theta}}{E[\theta]}$.

(c) The global class is not asymptotically stable if $\frac{C+K}{c+k}$ is sufficiently low and either

(i) $W$ is sufficiently high and $\lambda<C$ or (ii) $\lambda$ is sufficiently low.

The results of corollaries 2(a) and (c) closely resemble those of corollaries 1(b)(i) and (ii). They suggest that if the scale benefits of a class action are high, the global class is more likely to be asymptotically stable under $\mathcal{R}^{2}$ if the plaintiffs' bargaining power in settlement negotiations is low, and that if the scale benefits of a class action are low, the global class is less likely to be asymptotically stable under $\mathcal{R}^{2}$ if the plaintiffs' probability of prevailing at trial is high or their bargaining power in settlement negotiations is low. Corollary 2(b) suggests that, irrespective of the plaintiffs' probability of prevailing at trial or bargaining power in settlement negotiations, the global class is likely to be asymptotically stable under $\mathcal{R}^{2}$ if the scale benefits of a class action are close to (but do not exceed) the ratio of the maximum damage claim to the expected damage claim.

It is interesting to note how the results of lemma 1 inform certain results of corollaries 1 and 2. First, corollaries 1(b)(i) and 2(a) indicate that even if the scale benefits of a class action are high, damage averaging may lead the global class to unravel if the plaintiffs' bargaining power in settlement negotiations is high. Lemma 1(c) suggests why: when the scale benefits of a class action are high, the probability of reaching a settlement (and realizing the benefits of their high bargaining power) is greater for opt-plaintiffs than it is for the global class. Second, corollaries 1(b)(ii) and 2(c) indicate that when the scale benefits of a class action are low, damage averaging may lead the global class to unravel if the plaintiffs' probability of prevailing at trial is high. Again lemma 1(c) suggests why: when the scale benefits of a class action are low, the probability of litigation (and realizing the benefits of their high probability of prevailing at trial) is greater for opt-out plaintiffs than it is for the global class.

The following proposition states that asymptotic stability of the global class under $\mathcal{R}^{1}$ necessarily implies asymptotic stability of the global class under $\mathcal{R}^{2}$ but not vice versa. 
Proposition 3 If the global class is asymptotically stable under $\mathcal{R}^{1}$, then the global class is asymptotically stable under $\mathcal{R}^{2}$. If the global class is asymptotically stable under $\mathcal{R}^{2}$, however, the global class may or may not be asymptotically stable under $\mathcal{R}^{1}$.

\subsection{Pro Rata by Outside Options $\left(\mathcal{R}^{3}\right)$}

The following proposition states that the global class is asymptotically stable if the net recovery of the class is allocated to the members pro rata in accordance with their outside options.

Proposition 4 Suppose the allocation rule is $\mathcal{R}^{3}$. Then the global class is asymptotically stable.

\section{$5 \quad$ Numerical Illustrations}

This section illustrates the stability results of the previous section with five numerical examples. In the examples, I assume that $\theta_{i}=(\bar{\theta}-\underline{\theta}) X_{i}+\underline{\theta}$, where $X_{i} \stackrel{i i d}{\sim} \operatorname{Beta}(\alpha, \beta)$. That is, I assume that $\theta_{i}$ follows a Beta distribution on the interval $[\underline{\theta}, \bar{\theta}]$ with shape parameters $\alpha$ and $\beta$. Under this assumption, the expected damage claim is $E[\theta]=(\bar{\theta}-\underline{\theta})\left(\frac{\alpha}{\alpha+\beta}\right)+\underline{\theta}$.

Table 1 summarizes the five examples. In each example, the probability that the plaintiffs would prevail at trial is high $(W=0.88)$ and the plaintiffs' bargaining power is settlement negotiations is low $(\lambda=0.23)$. The other case variables are varied across the examples to illustrate how the asymptotic stability of the global class depends on the characteristics of the case.

Table 1: Summary of Five Examples

\begin{tabular}{cccccc}
\hline & \multicolumn{5}{c}{ Example Number } \\
\cline { 2 - 6 } Variable & 1 & 2 & 3 & 4 & 5 \\
\hline$\underline{\bar{\theta}}$ & 8 & 30 & 30 & 8 & 30 \\
$\alpha$ & 40 & 40 & 40 & 40 & 40 \\
$\beta$ & 6 & 6 & 6 & 6 & 15 \\
$W$ & 15 & 15 & 15 & 15 & 6 \\
$\lambda$ & 0.88 & 0.88 & 0.88 & 0.88 & 0.88 \\
$\frac{C+K}{c+k}$ & 0.23 & 0.23 & 0.23 & 0.23 & 0.23 \\
\hline
\end{tabular}

Example 1 This example illustrates a classic case of asymptotic instability: the plaintiffs' damage claims are positively skewed over a wide range and the scale benefits of a class action are low. The global class is asymptotically stable neither if the net recovery of the class is allocated equally among the members nor if it is allocated pro rata in accordance with the members' damage claims. 
$\mathcal{R}^{1}$ : Not asymptotically stable

$E[\theta]=17<32=\bar{\theta}-\underline{\theta}$

$\mathcal{R}^{2}$ : Not asymptotically stable

$\frac{C+K}{c+k}=1.1<2.4=\frac{\bar{\theta}}{E[\theta]} \& W=0.88$

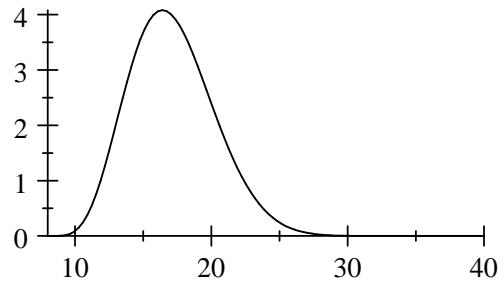

Density of $\theta$

Example 2 Like example 1, this example has positively skewed damage claims and low scale benefits. The key difference is that the range of damage claims is narrow. This example illustrates that, even with a narrow range of damage claims, low scale benefits can lead to the asymptotic instability of the global class under $\mathcal{R}^{1}$ and $\mathcal{R}^{2}$.

$\mathcal{R}^{1}$ : Not asymptotically stable

$$
\begin{aligned}
& E[\theta]=33>10=\bar{\theta}-\underline{\theta} \\
& \frac{C+K}{c+k}=1.1<1.2=\frac{\bar{\theta}}{E[\theta]} \& W=0.88
\end{aligned}
$$

$\mathcal{R}^{2}$ : Not asymptotically stable

$\frac{C+K}{c+k}=1.1<1.2=\frac{\bar{\theta}}{E[\theta]} \& W=0.88$

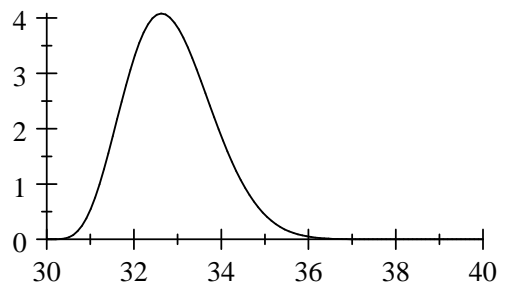

Density of $\theta$

Example 3 Like example 2, this example has positively skewed but narrowly ranging damage claims. The key difference is that the scale benefits of a class action are high, which reverses the result. Now the global class is asymptotically stable under both $\mathcal{R}^{1}$ and $\mathcal{R}^{2}$.

$$
\begin{aligned}
& \mathcal{R}^{1}: \text { Asymptotically stable } \\
& E[\theta]=33>10=\bar{\theta}-\underline{\theta} \\
& \quad \frac{C+K}{c+k}=3.0>1.2=\frac{\bar{\theta}}{E[\theta]} \& \lambda=0.23 \\
& \mathcal{R}^{2}: \text { Asymptotically stable } \\
& \quad \frac{C+K}{c+k}=3.0>1.2=\frac{\bar{\theta}}{E[\theta]} \& \lambda=0.23
\end{aligned}
$$

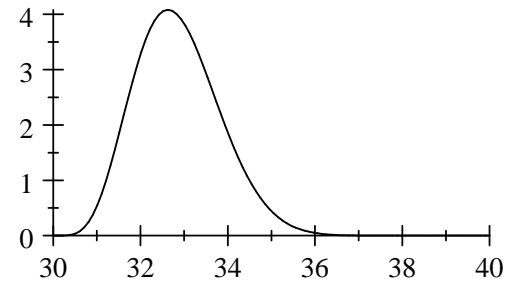

Density of $\theta$

Example 4 Like example 1, this example has positively skewed and widely ranging damage claims. The key difference is that, like example 3 , the scale benefits of a class action are high. Here the class is asymptotically stable under $\mathcal{R}^{2}$ but not under $\mathcal{R}^{1}$, illustrating that pivotal role that the shape of the distribution of the plaintiffs' damage claims plays in determining the asymptotic stability of the global class under equal sharing. 
$\mathcal{R}^{1}$ : Not asymptotically stable

$E[\theta]=17<32=\bar{\theta}-\underline{\theta}$

$\mathcal{R}^{2}$ : Asymptotically stable

$\frac{C+K}{c+k}=3.0>2.4=\frac{\bar{\theta}}{E[\theta]} \& \lambda=0.23$

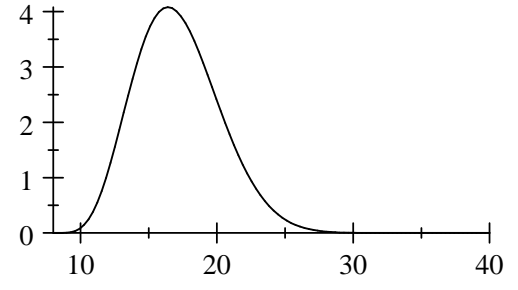

Density of $\theta$

Example 5 This example illustrates a classic case of asymptotic stability: the plaintiffs' damage claims are negatively skewed over a narrow range and the scale benefits of a class action are high. The global class is asymptotically stable whether the net recovery of the class is allocated equally among the members or pro rata in accordance with the members' damage claims. It is noteworthy that here, because of the favorable shape of the claims distribution, even more modest scale benefits (e.g., half the assumed scale benefits) would lead to the asymptotic stability of the global class under both allocation rules.

$$
\begin{aligned}
& \mathcal{R}^{1}: \text { Asymptotically stable } \\
& E[\theta]=37>10=\bar{\theta}-\underline{\theta} \\
& \quad \frac{C+K}{c+k}=3.0>1.1=\frac{\bar{\theta}}{E[\theta]} \& \lambda=0.23 \\
& \mathcal{R}^{2}: \text { Asymptotically stable } \\
& \quad \frac{C+K}{c+k}=3.0>1.1=\frac{\bar{\theta}}{E[\theta]} \& \lambda=0.23
\end{aligned}
$$

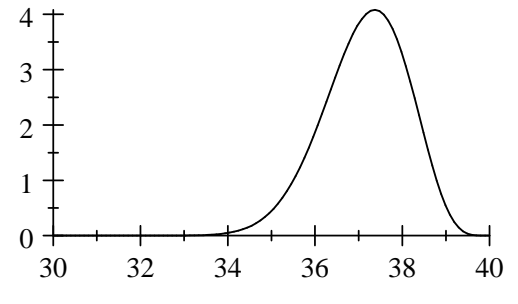

Density of $\theta$

\section{Concluding Remarks}

I examine the asymptotic stability of the global class in a Rule 23(b)(3) mass tort class action under three rules for allocating the net recovery of the class among its members: (1) equal sharing; (2) pro rata by damage claims; and (3) pro rata by outside options. I analyze a two-stage model of class action formation in which a single defendant faces multiple plaintiffs with heterogeneous damage claims. A global class action is certified at the outset. In stage 1, the formation of the class is modeled as a noncooperative, simultaneous move, single coalition formation game in partition function form. In stage 2, the resolution via litigation or settlement of the class action and any individual actions by opt-out plaintiffs is modeled in the divergent expectations tradition.

I show that the global class is asymptotically stable under rule 3 , but may not be asymptotically stable under rules 1 and 2. The shape of the distribution of the plaintiffs' damage claims proves to be a key determinant of class stability under rule 1. In particular, I find that the global class is more likely to be asymptotically stable under rule 1 if the expected damage claim is high and the 
range of damage claims is narrow, which suggests that if the distribution of the plaintiffs' damage claims is unimodal then the global class is more likely to be asymptotically stable under rule 1 if the distribution is negatively skewed. I also find that the scale benefits of the class action and the plaintiffs' probability of prevailing at trial and their bargaining power in settlement negotiations are important determinants of class stability. Under rules 1 and 2, the global class is more likely to be asymptotically stable when the scale benefits of a class action are high and when the plaintiffs' bargaining power in settlement negotiations is low. When the scale benefits of a class action are low, the global class is less likely to be asymptotically stable under rules 1 and 2 if the plaintiffs' probability of prevailing at trial is high or their bargaining power in settlement negotiations is low.

My results highlight a general tradeoff between ex ante and ex post efficiency in selecting an allocation rule in a Rule 23(b)(3) mass tort class action. The tradeoff exists because the governing allocation rule's degree of damage averaging is positively related to the risk that the class will unravel due to adverse selection but negatively related to the cost of implementing the allocation rule. More importantly, however, the results also provide guidance regarding when this tradeoff may be avoided. For instance, the class is unlikely to unravel under partial damage averaging if the class action achieves large economies of scale and the plaintiffs have low bargaining power in settlement negotiations. If, in addition, the plaintiffs have negatively skewed damage claims over a narrow range, then the class is unlikely to unravel even under full damage averaging.

This guidance, in turn, suggests criteria for evaluating the requirements for class certification under Rule 23(b)(3). For example, if the plaintiffs' damage claims are positively skewed over a wide range then perhaps the court should not find that "questions of law or fact common to class members predominate over any questions affecting only individual members" (Fed. R. Civ. P. 23(b)(3)). Similarly, if even a mild degree of damage averaging is likely to destabilize the class then perhaps a class action is not "superior to other available methods for . . . efficiently adjudicating the controversy" (Fed. R. Civ. P. 23(b)(3)); cf. Shapiro 1998). My results also suggest criteria evaluating the requirements for approving settlements under Rule 23(e). For instance, if the proposed allocation plan is likely to destabilize the class then perhaps the court should not find that the settlement is "fair, reasonable, and adequate" (Fed. R. Civ. P. 23(e)(2)) on the grounds that the plan is not an effective method of distributing relief to the class (Fed. R. Civ. P. 23(e)(2)(c)(ii)). Given that class actions scholars (and presumably courts) view the standards for judicial review of class action settlements as "confused" and the numerous multifactor tests elaborated by courts as "uncertain in scope, ambiguous in meaning and undefined in weight" (Macey \& Miller, 2009, pp. 167-168), this would appear to be a welcome contribution. ${ }^{12}$

There are several ways in which this paper could be extended. First, we could relax the assumption that each opt-out plaintiff must pursue its claim individually. This would require redefining the stability concept from Nash equilibrium to strong Nash equilibrium (Aumann, 1959) or coalition-

\footnotetext{
${ }^{12}$ Although the 2018 amendments to Rule 23 attempt to reduce this confusion by codifying the factors to be considered by a court in reviewing a proposed settlement, unless and until the courts develop consistent interpretations of these factors, they will remain "uncertain in scope, ambiguous in meaning and undefined in weight" (Macey \& Miller, 2009, pp. 167-168).
} 
proof Nash equilibrium (Bernheim, Peleg, \& Whinston, 1987). ${ }^{13}$ Although allowing plaintiffs to form subcoalitions would make the analysis more general, ${ }^{14}$ it is not warranted in our setting. The assumption that opt-out plaintiff pursue their claims individually rests on two presumptions, each of which is consistent with the premise that a global class action has been certified under Rule 23(b)(3). First, it presumes that no other court would certify a separate class action on behalf of some or all opt-out plaintiffs, which is consistent with the fact that the court did not deem it appropriate to divide the global class into subclasses (Fed. R. Civ. P. 23(c)(5)). Second, it presumes that search costs, personal jurisdiction requirements, or other transaction costs preclude opt-out plaintiffs from maintaining one or more joinder actions under Rule 20, which is consistent with the fact that the court determined that "the class is so numerous that joinder of all members is impracticable" (Fed. R. Civ. P. 23(a)(1)).

Second, we could relax the assumption that there are no externalities or spillovers across plaintiffs. In particular, we could assume that the class action is resolved first and that the existence or size of the class affects the expected recovery of opt-out plaintiffs. ${ }^{15}$ For example, we could assume that the class action increases the probability that opt-out plaintiffs would prevail at trial due to the potential for a factual or legal determination in favor of the class to be given preclusive effect against the defendant in a subsequent individual action by an opt-out plaintiff under the doctrine of nonmutual offensive collateral estoppel. ${ }^{16}$ We also could relax the assumptions that the defendant's assets are sufficient to satisfy all damage claims and that all plaintiffs have the same priority in bankruptcy. Instead, we could assume that the class action reduces the expected payoff for opt-out plaintiffs due to the potential that, after the resolution of the class action, the defendant will not have sufficient assets available to satisfy the damage claims of all opt-out plaintiffs.

Third, we could relax the symmetry assumptions. For instance, we could consider the possibility that the class may enjoy enhanced bargaining as compared to individual plaintiffs (Silver, 2000; Che, 2002). We also could imagine that a plaintiff's bargaining power may be a function of the probability that it would prevail at trial.

Fourth, we could extend the model to give class members a second opportunity to opt out in stage 2 in the event of a proposed settlement of the class action. Extending the model to include a second opt-out would be consistent with the 2003 amendments to Rule 23, which, inter alia,

\footnotetext{
${ }^{13}$ Informally, a strategy profile constitutes a strong Nash equilibrium (SNE) if it is immune to deviations by coalitions. A strategy profile constitutes a coalition-proof Nash equilibrium (CPNE) if it is immune to credible deviations by coalitions, i.e., coalitional deviations that themselves are immune to further deviations by subcoalitions. For formal definitions of SNE and CPNE, see, e.g., Bloch (2003).

${ }^{14}$ One consequence of relaxing this assumption would be that proposition 3 would no longer hold; that is, allocating the net recovery of the class to the members pro rata in accordance with their outside options would no longer ensure the asymptotic stability of the global class.

${ }^{15}$ We also could consider making the timing of litigation/settlement endogenous, as in Marceau \& Mongrain (2003).

${ }^{16}$ Under this assumption, if the class settles or losses at trial, the probability that an opt-out plaintiff prevails in a subsequent trial is $W$, but if the class prevails at trial, the probability that an opt-out plaintiff prevails in a subsequent trial is $Y>W$. Accordingly, the ex ante probability that an opt-out plaintif would prevail at trial is $W^{+}=\left[\phi_{A}+\left(1-\phi_{A}\right)(1-W)\right] W+\left[\left(1-\phi_{A}\right) W\right] Y>W$. The class action, therefore, increases the expected payoff of pursuing individual litigation against the defendant, which serves to undermine the stability of the global class.
} 
authorizes the court to refuse to approve a settlement in a previously certified Rule 23(b)(3) class action unless it affords class members a new opportunity to opt out (see Fed. R. Civ. P. 23(e)(4)).

Lastly, we could generalize the model to cover all possible allocations rules (i.e., all degrees of damage averaging). This would entail modeling the recovery to a plaintiff as a linear combination of his own damage claim and the average damage claim of the class. We also could modify or generalize the model to apply to or encompass other nonmandatory claim aggregation mechanisms.

\section{Appendix A: Distribution of $\Delta(W)$}

Let $\varepsilon, \mu \sim \operatorname{Uniform}(a, b)$ and define $\Delta=\varepsilon-\mu$. It can be shown that the probability density function of $\Delta$ is

$$
f_{\Delta}(z)= \begin{cases}\frac{z+(b-a)}{(b-a)^{2}} & a-b \leq z \leq 0 \\ \frac{(b-a)-z}{(b-a)^{2}} & 0<z \leq b-a \\ 0 & \text { otherwise }\end{cases}
$$

It follows that the cumulative distribution function of $\Delta$ is

$$
F_{\Delta}(z)=\left\{\begin{array}{ll}
0 & z<a-b \\
\frac{1}{2}\left(\frac{z+(b-a)}{(b-a)}\right)^{2} & a-b \leq z \leq 0 \\
1-\frac{1}{2}\left(\frac{(b-a)-z}{(b-a)}\right)^{2} & 0<z \leq b-a \\
1 & z \geq b-a
\end{array} .\right.
$$

If $W \in\left[0, \frac{1}{2}\right]$, then $a=-W$ and $b=W$, which implies

$$
f_{\Delta(W)}(z)= \begin{cases}\frac{z+2 W}{4 W^{2}} & -2 W \leq z \leq 0 \\ \frac{2 W-z}{4 W^{2}} & 0<z \leq 2 W \\ 0 & \text { otherwise }\end{cases}
$$

and

$$
F_{\Delta(W)}(z)=\left\{\begin{array}{ll}
0 & z<-2 W \\
\frac{1}{2}\left(\frac{z+2 W}{2 W}\right)^{2} & -2 W \leq z \leq 0 \\
1-\frac{1}{2}\left(\frac{2 W-z}{2 W}\right)^{2} & 0<z \leq 2 W \\
1 & z>2 W
\end{array} .\right.
$$

If $W \in\left[\frac{1}{2}, 1\right]$, then $a=W-1$ and $b=1-W$, which implies

$$
f_{\Delta(W)}(z)= \begin{cases}\frac{z+2(1-W)}{4(1-W)^{2}} & 2(W-1) \leq z \leq 0 \\ \frac{2(1-W)-z}{4(1-W)^{2}} & 0<z \leq 2(1-W) \\ 0 & \text { otherwise }\end{cases}
$$


and

$$
F_{\Delta(W)}(z)=\left\{\begin{array}{ll}
0 & z<2(W-1) \\
\frac{1}{2}\left(\frac{z+2(1-W)}{2(1-W)}\right)^{2} & 2(W-1) \leq z \leq 0 \\
1-\frac{1}{2}\left(\frac{2(1-W)-z}{2(1-W)}\right)^{2} & 0<z \leq 2(1-W) \\
1 & z>2(1-W)
\end{array} .\right.
$$

Figures 1 and 2 depict $f_{\Delta(W)}(z)$ and $F_{\Delta(W)}(z)$ for $W=0.25,0.5$, and 0.75 . As illustrated by figure 1 , the density of $\Delta(W)$ is a symmetric tent (centered at $z=0$ ) whose peak decreases to 1 as $W$ increases from 0 to 0.5 and then increases as $W$ increases from 0.5 to 1 . Similarly, as illustrated by figure 2, the distribution of $\Delta(W)$ is a symmetric $S$ (through $\left.F_{\Delta(W)}(0)=0.5\right)$ whose slope decreases as $W$ increases from 0 to 0.5 and then increases as $W$ increases from 0.5 to 1 . Furthermore, it can be shown that $F_{\Delta(W)}(z)$ is continuous in $W$.

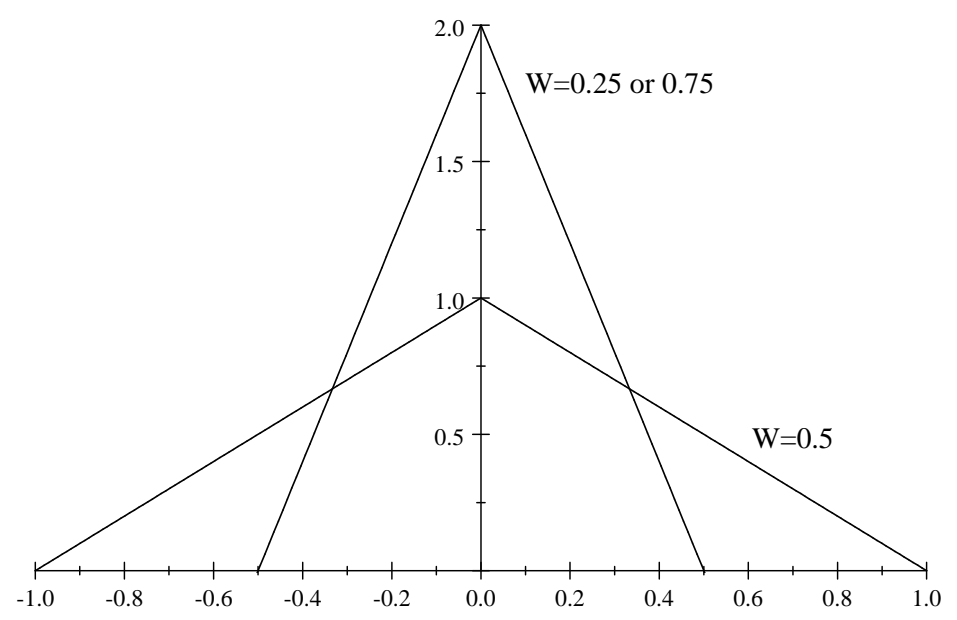

Figure 1: Density of $\Delta(W)$ for $W=0.25,0.5$, and 0.75 .

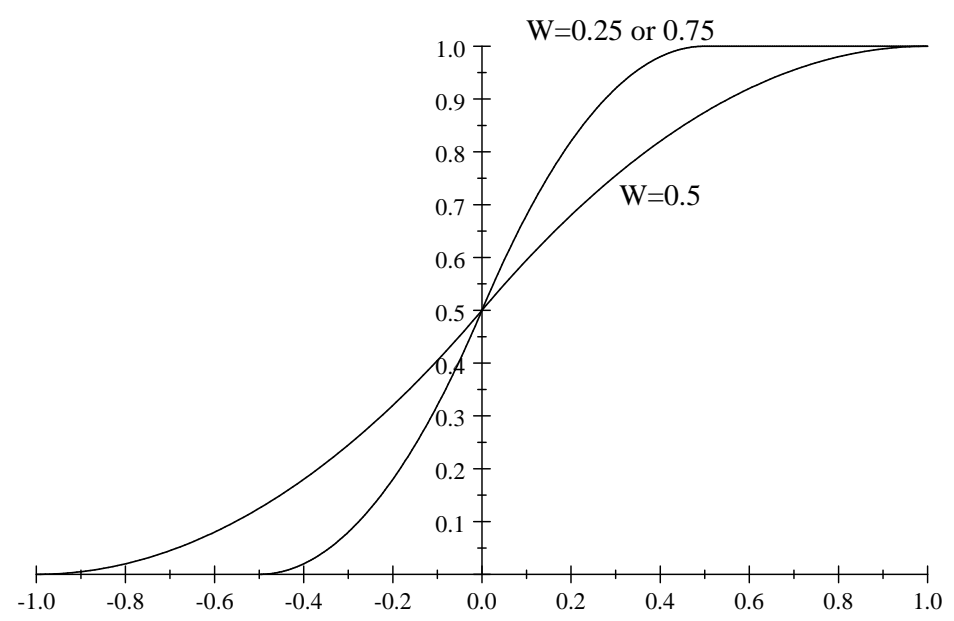

Figure 2: Distribution of $\Delta(W)$ for $W=0.25,0.5$, and 0.75 . 


\section{Appendix B: Proofs}

\section{Proof of lemma 1}

(a) Follows immediately from the fact that $F_{\Delta(W)}$ is nondecreasing.

(b) By assumptions (6)-(8) and because $f_{\theta}$ is strictly positive on $[\underline{\theta}, \bar{\theta}]$, we have $\frac{C+K}{\frac{1}{(}\left(C_{N}+K_{N}\right)} \geq 1>$ $\frac{\theta_{(1)}}{\frac{1}{n} \theta_{N}}$. Because $F_{\Delta(W)}$ is nondecreasing, this implies $\phi_{(1)}=F_{\Delta(W)}\left(\frac{C+K}{\theta_{(1)}}\right) \geq F_{\Delta(W)}\left(\frac{C_{N}+K_{N}}{\theta_{N}}\right)=\phi_{N}$.

(c) (i) For any $\varepsilon>0, \operatorname{Pr}\left(\left|\theta_{(n)}-\bar{\theta}\right| \geq \varepsilon\right)=\operatorname{Pr}\left(\theta_{(n)} \geq \bar{\theta}+\varepsilon\right)+\operatorname{Pr}\left(\theta_{(n)} \leq \bar{\theta}-\varepsilon\right)$. Note that $\operatorname{Pr}\left(\theta_{(n)} \geq \bar{\theta}+\varepsilon\right)=0$ (because $\theta_{i} \leq \bar{\theta}$ for all $\left.i \in N\right)$. Note further that $\operatorname{Pr}\left(\theta_{(n)} \leq \bar{\theta}-\varepsilon\right)=$ $\left[F_{\theta}(\bar{\theta}-\varepsilon)\right]^{n}$ (see, e.g., Casella \& Berger, 2002, thm. 5.4.4) and that $F_{\theta}(\bar{\theta}-\varepsilon) \in[0,1$ ) (because $\bar{\theta}$ is the upper bound of the support set of $\left.F_{\theta}\right)$. It follows that $\lim _{n \rightarrow \infty} \operatorname{Pr}\left(\left|\theta_{(n)}-\bar{\theta}\right| \geq \varepsilon\right)=$ $\lim _{n \rightarrow \infty}\left[F_{\theta}(\bar{\theta}-e)\right]^{n}=0$.

(ii)-(iii) Because $F_{\Delta(W)}$ is continuous, $\operatorname{plim}_{n \rightarrow \infty} \phi_{(n)}=F_{\Delta(W)}\left(\frac{C+K}{\bar{\theta}}\right)$ and $\operatorname{plim}_{n \rightarrow \infty} \phi_{N}=$ $F_{\Delta(W)}\left(\frac{c+k}{E[\theta]}\right)$ by the continuous mapping theorem. Because $F_{\Delta(W)}$ is nondecreasing, $\bar{\theta}>\left(\frac{C+K}{c+k}\right) E[\theta]$ implies $\operatorname{plim}_{n \rightarrow \infty}\left(\phi_{(n)}-\phi_{N}\right)=\operatorname{plim}_{n \rightarrow \infty} \phi_{(n)}-\operatorname{plim}_{n \rightarrow \infty} \phi_{N} \leq 0$ and $\bar{\theta}<\left(\frac{C+K}{c+k}\right) E[\theta] \operatorname{implies}$ $\operatorname{plim}_{n \rightarrow \infty}\left(\phi_{(n)}-\phi_{N}\right)=\operatorname{plim}_{n \rightarrow \infty} \phi_{(n)}-\operatorname{plim}_{n \rightarrow \infty} \phi_{N} \geq 0$.

\section{Proof of proposition 1}

Under $\mathcal{R}^{1}$, for all $i \in N$,

$$
\begin{aligned}
v_{i}\left(\Omega^{N}\right) & =\frac{1}{n} E\left[\pi_{N}\right] \\
& =\phi_{N} \lambda\left(E\left[Q_{N}\right] \frac{\theta_{N}}{n}+\frac{K_{N}}{n}\right)+\left(1-\phi_{N} \lambda\right)\left(E\left[P_{N}\right] \frac{\theta_{N}}{n}-\frac{C_{N}}{n}\right) \\
& =\left(W \frac{\theta_{N}}{n}-\frac{C_{N}}{n}\right)+\phi_{N} \lambda\left(\frac{C_{N}+K_{N}}{n}\right) .
\end{aligned}
$$

In addition, for all $i \in N$,

$$
\begin{aligned}
v_{i}\left(\Omega_{-i}^{N}\right) & =E\left[\pi_{i}\right] \\
& =\phi_{i} \lambda\left(E\left[Q_{i}\right] \theta_{i}+K\right)+\left(1-\phi_{i} \lambda\right)\left(E\left[P_{i}\right] \theta_{i}-C_{i}\right) \\
& =\left(W \theta_{i}-C\right)+\phi_{i} \lambda(C+K) .
\end{aligned}
$$

Note $\operatorname{plim}_{n \rightarrow \infty}\left(v_{i}\left(\Omega^{N}\right)-v_{i}\left(\Omega_{-i}^{N}\right)\right) \geq 0 \Leftrightarrow \operatorname{plim}_{n \rightarrow \infty} v_{i}\left(\Omega^{N}\right)-\operatorname{plim}_{n \rightarrow \infty} v_{i}\left(\Omega_{-i}^{N}\right) \geq 0$. Without loss of generality, label the plaintiff with the highest damage claim as plaintiff $(n)$. That is, $\theta_{(n)}=$ $\max _{1 \leq i \leq n} \theta_{i}$. Because $\theta_{(n)} \geq \theta_{i}$ and $\phi_{(n)} \leq \phi_{i}$ for all $i \in N$, we have $\operatorname{plim}_{n \rightarrow \infty} v_{(n)}\left(\Omega_{-(n)}^{N}\right) \geq$ $\operatorname{plim}_{n \rightarrow \infty} v_{i}\left(\Omega_{-i}^{N}\right)$ for all $i \in N$. It follows that $\operatorname{plim}_{n \rightarrow \infty}\left(v_{i}\left(\Omega^{N}\right)-v_{i}\left(\Omega_{-i}^{N}\right)\right) \geq 0$ for all $i \in N \Leftrightarrow$ $\operatorname{plim}_{n \rightarrow \infty} v_{(n)}\left(\Omega^{N}\right)-\operatorname{plim}_{n \rightarrow \infty} v_{(n)}\left(\Omega_{-(n)}^{N}\right) \geq 0$. 
By assumption, $\frac{\theta_{N}}{n}=\frac{E[\theta] \cdot n}{n}=E[\theta]$. By assumption (8), $\operatorname{plim}_{n \rightarrow \infty} \frac{C_{N}}{n}=c$ and $\operatorname{plim}_{n \rightarrow \infty} \frac{C_{N}+K_{N}}{n}=$ $c+k$. By lemma 1(c), $\operatorname{plim}_{n \rightarrow \infty} \phi_{N}=F_{\Delta(W)}\left(\frac{c+k}{E[\theta]}\right), \operatorname{plim}_{n \rightarrow \infty} \theta_{(n)}=\bar{\theta}$, and $\operatorname{plim}_{n \rightarrow \infty} \phi_{(n)}=$ $F_{\Delta(W)}\left(\frac{C+K}{\bar{\theta}}\right)$. Thus,

$$
\begin{aligned}
\operatorname{plim}_{n \rightarrow \infty} v_{(n)}\left(\Omega^{N}\right) & =\operatorname{plim}_{n \rightarrow \infty}\left[\left(W \frac{\theta_{N}}{n}-\frac{C_{N}}{n}\right)+\phi_{N} \lambda\left(\frac{C_{N}+K_{N}}{n}\right)\right] \\
& =(W E[\theta]-c)+\lambda F_{\Delta(W)}\left(\frac{c+k}{E[\theta]}\right)(c+k)
\end{aligned}
$$

and

$$
\begin{aligned}
\operatorname{plim}_{n \rightarrow \infty} v_{(n)}\left(\Omega_{-(n)}^{N}\right) & =\operatorname{plim}_{n \rightarrow \infty}\left[\left(W \theta_{(n)}-C\right)+\phi_{(n)} \lambda(C+K)\right] \\
& =(W \bar{\theta}-C)+\lambda F_{\Delta(W)}\left(\frac{C+K}{\bar{\theta}}\right)(C+K) .
\end{aligned}
$$

Therefore, $\operatorname{plim}_{n \rightarrow \infty}\left(v_{i}\left(\Omega^{N}\right)-v_{i}\left(\Omega_{-i}^{N}\right)\right) \geq 0$ for all $i \in N$

$$
\begin{gathered}
\Leftrightarrow(W E[\theta]-c)+\lambda F_{\Delta(W)}\left(\frac{c+k}{E[\theta]}\right)(c+k)-(W \bar{\theta}-C)-\lambda F_{\Delta(W)}\left(\frac{C+K}{\bar{\theta}}\right)(C+K) \geq 0 \\
\Leftrightarrow \bar{\theta} \leq E[\theta]+\frac{1}{W}\left((C-c)+\lambda\left[F_{\Delta(W)}\left(\frac{c+k}{E[\theta]}\right)(c+k)-F_{\Delta(W)}\left(\frac{C+K}{\bar{\theta}}\right)(C+K)\right]\right) .
\end{gathered}
$$

\section{Proof of corollary 1}

(a) Assume $E[\theta]<\bar{\theta}-\underline{\theta}$. It follows that $\bar{\theta}>E[\theta]+\xi_{1}$ if $\xi_{1} \leq \underline{\theta}$. By definition,

$$
\xi_{1}=\frac{1}{W}\left((C-c)+\lambda\left[F_{\Delta(W)}\left(\frac{c+k}{E[\theta]}\right)(c+k)-F_{\Delta(W)}\left(\frac{C+K}{\bar{\theta}}\right)(C+K)\right]\right) .
$$

Let

$$
\Gamma=\lambda\left[F_{\Delta(W)}\left(\frac{c+k}{E[\theta]}\right)(c+k)-F_{\Delta(W)}\left(\frac{C+K}{\bar{\theta}}\right)(C+K)\right] .
$$

If $\Gamma<0$, then $\xi_{1} \leq \frac{C}{W} \leq \underline{\theta}$ because $W \underline{\theta}-C \geq 0$. If $\Gamma>0$, then

$$
\xi_{1} \leq \frac{1}{W}\left((C-c)+\left[(c+k)-\frac{1}{2}(C+K)\right]\right)
$$

because $\lambda \in[0,1]$ and $F_{\Delta(W)}(z) \in\left[\frac{1}{2}, 1\right]$ for $z \geq 0$. It follows that

$$
\xi_{1} \leq \frac{1}{2}\left(\frac{C}{W}+\frac{K}{W}\right) \leq \underline{\theta}
$$

because $k \leq K, W \underline{\theta}-C \geq 0$, and $W \underline{\theta}-K \geq 0$.

(b) (i) Assume $E[\theta]>\bar{\theta}-\underline{\theta}$. Suppose $\lambda=0$. Then $\xi_{1}=\frac{C-c}{W}$. Recall that $W \underline{\theta}-C \geq 0$. It follows that $\xi_{1} \leq \underline{\theta}-\frac{c}{W}$. Because $C+K \leq 2 W \underline{\theta}, \frac{C+K}{c+k} \rightarrow \infty$ implies $c+k \rightarrow 0$, which in turn 
implies $c \rightarrow 0$. Therefore, $\xi_{1} \rightarrow \underline{\theta}$ from below as $\frac{C+K}{c+k} \rightarrow \infty$. It follows that there exists $x>0$ such that $\frac{C+K}{c+k}>x$ implies $E[\theta]+\underline{\theta}>E[\theta]+\xi_{1}>\bar{\theta}$. Therefore, by continuity of $\xi_{1}$, there exist $\delta_{\lambda}>0$ and $x>0$ such that if $\lambda<\delta_{\lambda}$ then $\frac{C+K}{c+k}>x$ implies $\bar{\theta}<E[\theta]+\xi_{1}$.

(ii) Suppose $\frac{C+K}{c+k}=1$ and $W=1$. Note that because $0<c \leq C$ and $0<k \leq K, \frac{C+K}{c+k}=1$ implies $C=c$. Note further that because $F_{\Delta(1)}\left(\frac{c+k}{E[\theta]}\right)=F_{\Delta(1)}\left(\frac{C+K}{\bar{\theta}}\right)=1, W=1$ implies $\xi_{1}=((C-c)+\lambda[(c+k)-(C+K)])$. It follows that $\xi_{1}=0$ when $\frac{C+K}{c+k}=1$ and $W=1$. Therefore, by continuity of $\xi_{1}$, there exist $\delta_{C}>1$ and $\delta_{W}<1$ such that if $\frac{C+K}{c+k}<\delta_{C}$ and $W>\delta_{W}$ then $\xi_{1}<\bar{\theta}-E[\theta]$. Now suppose $\frac{C+K}{c+k}=1$ and $\lambda=0$. Because $\frac{C+K}{c+k}=1 \mathrm{implies} C=c$, it follows that $\xi_{1}=0$. Therefore, by continuity of $\xi_{1}$, there exist $\delta_{C}>1$ and $\delta_{\lambda}>0$ such that if $\frac{C+K}{c+k}<\delta_{C}$ and $\lambda<\delta_{\lambda}$ then $\xi_{1}<\bar{\theta}-E[\theta]$.

\section{Proof of proposition 2}

Under $\mathcal{R}^{2}$, for all $i \in N$,

$$
\begin{aligned}
v_{i}\left(\Omega^{N}\right) & =\frac{\theta_{i}}{\theta_{N}} E\left[\pi_{N}\right]=\frac{\theta_{i}}{\frac{1}{n} \theta_{N}} \frac{1}{n} E\left[\pi_{N}\right] \\
& =\frac{\theta_{i}}{\frac{1}{n} \theta_{N}}\left[\left(W \frac{\theta_{N}}{n}-\frac{C_{N}}{n}\right)+\phi_{N} \lambda\left(\frac{C_{N}+K_{N}}{n}\right)\right] .
\end{aligned}
$$

Without loss of generality, label the plaintiff with the highest damage claim as plaintiff $(n)$. By the same logic set forth in the proof of proposition 1, it follows that $\operatorname{plim}_{n \rightarrow \infty}\left(v_{i}\left(\Omega^{N}\right)-v_{i}\left(\Omega_{-i}^{N}\right)\right) \geq 0$ for all $i \in N \Leftrightarrow \operatorname{plim}_{n \rightarrow \infty} v_{(n)}\left(\Omega^{N}\right)-\operatorname{plim}_{n \rightarrow \infty} v_{(n)}\left(\Omega_{-(n)}^{N}\right) \geq 0$. Now

$$
\begin{aligned}
\operatorname{plim}_{n \rightarrow \infty} v_{(n)}\left(\Omega^{N}\right) & =\operatorname{plim}_{n \rightarrow \infty}\left(\frac{\theta_{(n)}}{\frac{1}{n} \theta_{N}}\left[\left(W \frac{\theta_{N}}{n}-\frac{C_{N}}{n}\right)+\phi_{N} \lambda\left(\frac{C_{N}+K_{N}}{n}\right)\right]\right) . \\
& =\frac{\bar{\theta}}{E[\theta]}\left[(W E[\theta]-c)+\lambda F_{\Delta(W)}\left(\frac{c+k}{E[\theta]}\right)(c+k)\right] .
\end{aligned}
$$

Therefore, $\operatorname{plim}_{n \rightarrow \infty}\left(v_{i}\left(\Omega^{N}\right)-v_{i}\left(\Omega_{-i}^{N}\right)\right) \geq 0$ for all $i \in N$

$$
\begin{aligned}
& \Leftrightarrow \frac{\bar{\theta}}{E[\theta]}\left[(W E[\theta]-c)+\lambda F_{\Delta(W)}\left(\frac{c+k}{E[\theta]}\right)(c+k)\right]-(W \bar{\theta}-C)-\lambda F_{\Delta(W)}\left(\frac{C+K}{\bar{\theta}}\right)(C+K) \geq 0 \\
& \Leftrightarrow W E[\theta] \bar{\theta}-c \bar{\theta}+\lambda \bar{\theta} F_{\Delta(W)}\left(\frac{c+k}{E[\theta]}\right)(c+k)-W E[\theta] \bar{\theta}+C E[\theta]-\lambda E[\theta] F_{\Delta(W)}\left(\frac{C+K}{\bar{\theta}}\right)(C+K) \geq 0 \\
& \Leftrightarrow \bar{\theta} \leq \frac{C}{c} E[\theta]+\frac{\lambda}{c}\left[\bar{\theta} F_{\Delta(W)}\left(\frac{c+k}{E[\theta]}\right)(c+k)-E[\theta] F_{\Delta(W)}\left(\frac{C+K}{\bar{\theta}}\right)(C+K)\right] .
\end{aligned}
$$




\section{Proof of corollary 2}

(a) Rewrite condition (10) as $\xi_{2} \geq \bar{\theta}-\frac{C}{c} E[\theta]$. This holds if

$$
\lambda\left[\bar{\theta} F_{\Delta(W)}\left(\frac{c+k}{E[\theta]}\right)(c+k)-E[\theta] F_{\Delta(W)}\left(\frac{C+K}{\bar{\theta}}\right)(C+K)\right] \geq c \bar{\theta}-C E[\theta] .
$$

Now if $\frac{C+K}{c+k}>\frac{\bar{\theta}}{E[\theta]}$, then $F_{\Delta(W)}\left(\frac{c+k}{E[\theta]}\right)<F_{\Delta(W)}\left(\frac{C+K}{\bar{\theta}}\right)$ because $F_{\Delta(W)}$ is nondecreasing. It follows that $\frac{C+K}{c+k}>\frac{\bar{\theta}}{E[\theta]} \frac{F_{\Delta(W)}\left(\frac{c+k}{E[\theta]}\right)}{F_{\Delta(W)}\left(\frac{C+K}{\bar{\theta}}\right)}$, or $\bar{\theta} F_{\Delta(W)}\left(\frac{c+k}{E[\theta]}\right)(c+k)<E[\theta] F_{\Delta(W)}\left(\frac{C+K}{\bar{\theta}}\right)(C+K)$. In addition, $\frac{C+K}{c+k}>\frac{\bar{\theta}}{E[\theta]}$ implies $c \bar{\theta}<C E[\theta]$. To see this, let $\frac{C+K}{c+k}=x$. Then we have $\frac{C}{c}=\left(1+\frac{k}{c}\right) x-\frac{K}{c}<x<\frac{\bar{\theta}}{E[\theta]}$. It follows that condition (10) holds if $\frac{C+K}{c+k}>\frac{\bar{\theta}}{E[\theta]}$ and $\lambda \leq \frac{c \bar{\theta}-C E[\theta]}{\bar{\theta} F_{\Delta(W)}\left(\frac{c+k}{E[\theta]}\right)(c+k)-E[\theta] F_{\Delta(W)}\left(\frac{C+K}{\bar{\theta}}\right)(C+K)}$.

(b) Suppose $\frac{C+K}{c+k} \leq \frac{\bar{\theta}}{E[\theta]}$. Then $F_{\Delta(W)}\left(\frac{c+k}{E[\theta]}\right)>F_{\Delta(W)}\left(\frac{C+K}{\bar{\theta}}\right)$. It follows that $\frac{C+K}{c+k} \leq$ $\frac{\bar{\theta}}{E[\theta]} \frac{F_{\Delta(W)}\left(\frac{c+k}{E[\theta]}\right)}{F_{\Delta(W)}\left(\frac{C+K}{\bar{\theta}}\right)}$, or $\bar{\theta} F_{\Delta(W)}\left(\frac{c+k}{E[\theta]}\right)(c+k) \geq E[\theta] F_{\Delta(W)}\left(\frac{C+K}{\bar{\theta}}\right)(C+K)$. Thus, $\frac{C+K}{c+k} \leq \frac{\bar{\theta}}{E[\theta]}$ implies $\xi_{2} \geq 0$. It follows that if $\frac{C+K}{c+k} \leq \frac{\bar{\theta}}{E[\theta]}$, then condition (10) holds if $\bar{\theta} \leq \frac{C}{c} E[\theta]$. Now let $\frac{C+K}{c+k}=x$. Then $\frac{C}{c}=\left(1+\frac{k}{c}\right) x-\frac{K}{c}$ and we can rewrite the foregoing condition as $\bar{\theta} \leq$ $\left(1+\frac{k}{c}\right) x-\frac{K}{c} E[\theta]$. This holds if $x \geq\left(\frac{\bar{\theta}}{E[\theta]}-\frac{K}{c}\right)\left(1+\frac{k}{c}\right)^{-1}$. Therefore, condition (10) holds if $\left(\frac{\bar{\theta}}{E[\theta]}-\frac{K}{c}\right)\left(1+\frac{k}{c}\right)^{-1} \leq \frac{C+K}{c+k} \leq \frac{\bar{\theta}}{E[\theta]}$.

(c) (i) Suppose $\frac{C+K}{c+k}=1, W=1$, and $C>\lambda$. Let $g=\frac{C}{c} E[\theta]+\xi_{2}$. We know from the proof of corollary $1(\mathrm{~b})(\mathrm{ii})$ that $\frac{C+K}{c+k}=1$ implies $C=c$ and that $W=1$ implies $\xi_{2}=$ $\frac{\lambda}{c}[\bar{\theta}(c+k)-E[\theta](C+K)]$. It follows that $g=\frac{\lambda}{C} \bar{\theta}-\left(1-\frac{\lambda}{C}\right) E[\theta]<\bar{\theta}$ when $\frac{C+K}{c+k}=1, W=1$, and $C>\lambda$. Therefore, by continuity of $g$, there exist $\delta_{C}>1$ and $\delta_{W}<1$ such that if $\frac{C+K}{c+k}<\delta_{C}$ and $W>\delta_{W}$ and $C>\lambda$ then $g<\bar{\theta}$.

(ii) Let $g=\frac{C}{c} E[\theta]+\xi_{2}$. From part (i) above we know that $C=c$ when $\frac{C+K}{c+k}=1$. It follows that $g=E[\theta]<\bar{\theta}$ when $\frac{C+K}{c+k}=1$ and $\lambda=0$. Therefore, by continuity of $g$, there exist $\delta_{C}>1$ and $\delta_{\lambda}>0$ such that if $\frac{C+K}{c+k}<\delta_{C}$ and $\lambda<\delta_{\lambda}$ then $g<\bar{\theta}$.

\section{Proof of proposition 3}

Assume $\bar{\theta} \leq E[\theta]+\xi_{1}$. This implies $\xi_{1}>0$ because $E[\theta]<\bar{\theta}$. It follows that

$$
\frac{1}{W}\left((C-c)+\lambda\left[F_{\Delta(W)}\left(\frac{c+k}{E[\theta]}\right)(c+k)-F_{\Delta(W)}\left(\frac{C+K}{\bar{\theta}}\right)(C+K)\right]\right)>0
$$

which implies

$$
\lambda F_{\Delta(W)}\left(\frac{c+k}{E[\theta]}\right)(c+k)>\lambda F_{\Delta(W)}\left(\frac{C+K}{\bar{\theta}}\right)(C+K)-(C-c) .
$$


Recall that $W \bar{\theta}-C>0, \underline{\theta}<E[\theta]<\bar{\theta}$, and $0<c \leq C$. This implies $W \bar{\theta}-c>W E[\theta]-c>0$. In addition, note that $\lambda F_{\Delta(W)}\left(\frac{c+k}{E[\theta]}\right)(c+k)>0$. It follows that

$$
\left(\frac{W \bar{\theta}-c}{c}\right)\left[\lambda F_{\Delta(W)}\left(\frac{c+k}{E[\theta]}\right)(c+k)\right]>\left(\frac{W E[\theta]-c}{c}\right)\left[\lambda F_{\Delta(W)}\left(\frac{C+K}{\bar{\theta}}\right)(C+K)-(C-c)\right]
$$

which implies

$$
\begin{aligned}
\left(\frac{W E[\theta]-c}{c}\right)(C-c)>\left(\frac{W E[\theta]-c}{c}\right)\left[\lambda F_{\Delta(W)}\left(\frac{C+K}{\bar{\theta}}\right)(C+K)\right] & -\left(\frac{W \bar{\theta}-c}{c}\right)\left[\lambda F_{\Delta(W)}\left(\frac{c+k}{E[\theta]}\right)(c+k)\right] .
\end{aligned}
$$

It follows that

$$
\begin{aligned}
\left(\frac{C-c}{c}\right) E[\theta]>\left(\frac{C-c}{W}\right)+\left(\frac{E[\theta]}{c}-\frac{1}{W}\right)\left[\lambda F_{\Delta(W)}\right. & \left.\left(\frac{C+K}{\bar{\theta}}\right)(C+K)\right] \\
& -\left(\frac{\bar{\theta}}{c}-\frac{1}{W}\right)\left[\lambda F_{\Delta(W)}\left(\frac{c+k}{E[\theta]}\right)(c+k)\right]
\end{aligned}
$$

which implies

$$
\begin{aligned}
\frac{C}{c} E[\theta]-E[\theta]>\frac{1}{W}((C-c) & \left.+\lambda\left[F_{\Delta(W)}\left(\frac{c+k}{E[\theta]}\right)(c+k)-F_{\Delta(W)}\left(\frac{C+K}{\bar{\theta}}\right)(C+K)\right]\right) \\
- & \frac{\lambda}{c}\left[\bar{\theta} F_{\Delta(W)}\left(\frac{c+k}{E[\theta]}\right)(c+k)-E[\theta] F_{\Delta(W)}\left(\frac{C+K}{\bar{\theta}}\right)(C+K)\right],
\end{aligned}
$$

or

$$
\frac{C}{c} E[\theta]-E[\theta]>\xi_{1}-\xi_{2}
$$

Hence, $E[\theta]+\xi_{1}<\frac{C}{c} E[\theta]+\xi_{2}$. Therefore, $\bar{\theta} \leq E[\theta]+\xi_{1}$ implies $\bar{\theta}<\frac{C}{c} E[\theta]+\xi_{2}$.

\section{Proof of proposition 4}

Under $\mathcal{R}^{3}$, for all $i \in N$,

$$
v_{i}\left(\Omega^{N}\right)=\frac{E\left[\pi_{i}\right]}{\sum_{j=1}^{n} E\left[\pi_{j}\right]} E\left[\pi_{N}\right]=\frac{E\left[\pi_{i}\right]}{\sum_{j=1}^{n} \frac{1}{n} E\left[\pi_{j}\right]} \frac{1}{n} E\left[\pi_{N}\right]
$$

Without loss of generality, label the plaintiff with the highest damage claim as plaintiff $(n)$. By the same logic set forth in the proof of proposition 1 , it follows that $\operatorname{plim}_{n \rightarrow \infty}\left(v_{i}\left(\Omega^{N}\right)-v_{i}\left(\Omega_{-i}^{N}\right)\right) \geq 0$ 
for all $i \in N \Leftrightarrow \operatorname{plim}_{n \rightarrow \infty}\left(v_{(n)}\left(\Omega^{N}\right)-v_{(n)}\left(\Omega_{-(n)}^{N}\right)\right) \geq 0$. Now

$$
\begin{aligned}
& \operatorname{plim}_{n \rightarrow \infty}\left(v_{(n)}\left(\Omega^{N}\right)-v_{(n)}\left(\Omega_{-(n)}^{N}\right)\right)=\operatorname{plim}_{n \rightarrow \infty}\left(\frac{E\left[\pi_{(n)}\right]}{\sum_{j=1}^{n} \frac{1}{n} E\left[\pi_{j}\right]} \frac{1}{n} E\left[\pi_{N}\right]-E\left[\pi_{(n)}\right]\right) \\
= & \operatorname{plim}_{n \rightarrow \infty}\left(\left(\frac{\frac{1}{n} E\left[\pi_{N}\right]}{\sum_{j=1}^{n} \frac{1}{n} E\left[\pi_{j}\right]}-1\right) E\left[\pi_{(n)}\right]\right) \\
= & \operatorname{plim}_{n \rightarrow \infty}\left(\left(\frac{W \frac{\theta_{N}}{n}-\frac{C_{N}}{n}+\phi_{N} \lambda\left(\frac{C_{N}+K_{N}}{n}\right)}{W \frac{\theta_{N}}{n}-C+\lambda\left(\frac{1}{n} \sum_{j=1}^{n} \phi_{j}\right)(C+K)}-1\right)\left[W \theta_{(n)}-C+\phi_{(n)} \lambda(C+K)\right]\right) \\
= & \left(\frac{W E[\theta]-c+\lambda F_{\Delta(W)}\left(\frac{c+k}{E[\theta]}\right)(c+k)}{W E[\theta]-C+\lambda\left(\operatorname{plim}_{n \rightarrow \infty}\left(\frac{1}{n} \sum_{j=1}^{n} \phi_{j}\right)\right)(C+K)}-1\right)\left[W \bar{\theta}-C+\lambda F_{\Delta(W)}\left(\frac{C+K}{\bar{\theta}}\right)(C+K)\right] .
\end{aligned}
$$

Note that

$$
\operatorname{plim}_{n \rightarrow \infty}\left(\frac{1}{n} \sum_{j=1}^{n} \phi_{j}\right)=\operatorname{plim}_{n \rightarrow \infty}\left(\frac{1}{n}\right)\left[\operatorname{plim}_{n \rightarrow \infty}\left(\sum_{j=1}^{n} \phi_{j}\right)\right]=\operatorname{plim}_{n \rightarrow \infty}\left(\frac{1}{n}\right) \int_{\frac{C+K}{\bar{\theta}}}^{\frac{C+K}{\underline{\theta}}} F_{\Delta(W)}(x) d x=0
$$

because $\int_{\frac{C+K}{\bar{\theta}}}^{\frac{C+K}{\underline{\theta}}} F_{\Delta(W)}(x) d x \leq \int_{\frac{C+K}{\bar{\theta}}}^{\frac{C+K}{\underline{\theta}}} d x=\frac{C+K}{\underline{\theta}}-\frac{C+K}{\bar{\theta}}<\infty$. In addition, note that

$$
(W E[\theta]-c)+\lambda F_{\Delta(W)}\left(\frac{c+k}{E[\theta]}\right)(c+k) \geq W E[\theta]-C
$$

because $C \geq c>0$ and $\lambda F_{\Delta(W)}\left(\frac{c+k}{E[\theta]}\right)(c+k) \geq 0$. Lastly, note that $W \bar{\theta}-C>0$ because $W \underline{\theta}-C \geq 0$ and $\underline{\theta}<\bar{\theta}$. Therefore, we have $\operatorname{plim}_{n \rightarrow \infty}\left(v_{(n)}\left(\Omega^{N}\right)-v_{(n)}\left(\Omega_{-(n)}^{N}\right)\right) \geq 0$.

\section{References}

Abraham, K. S. (1987). Individual action and collective responsibility: The dilemma of mass tort reform. Virginia Law Review, 73, 845-907.

Aumann, R. J. (1959). Acceptable points in general cooperate n-person games. In A. W. Tucker \& D. R. Luce (Eds.), Contributions to the Theory of Games, Volume IV. Princeton, NJ: Princeton University Press, 287-324.

Baker, L. A. \& Silver, C. (1997). Mass lawsuits and the aggregate settlement rule. Wake Forest Law Review, 32, 733-780.

Bernheim, B. D., Peleg, B., \& Whinston, M. D. (1987). Coalition-proof Nash equilibria I. Concepts. Journal of Economic Theory, 42, 1-12. 
Bloch, F. (1997). Non-cooperative methods of coalition formation in games with spillovers. In C. Carraro \& D. Siniscalco (Eds.), New Directions in the Economic Theory of the Environment. Cambridge: Cambridge University Press, 311-352.

Bloch, F. (2003). Non-cooperative models of coalition formation in games with spillovers. In C. Carraro (Ed.), The Endogenous Formation of Economic Coalitions. Cheltenham, UK: Edward Elgar, $35-79$.

Bone, R. G. (2003). Civil Procedure: The Economics of Civil Procedure. New York: Foundation Press.

Bronsteen, J. \& Fiss, O. (2003). The class action rule. Notre Dame Law Review, 78, 1419-1453.

Campos, S. J. (2012). Mass torts and due process. Vanderbilt Law Review, 65, 1059-1121.

Casella, G. \& Berger, R. L. (2002). Statistical Inference, Second Edition. Pacific Grove, CA: Duxbury, 2nd edition.

Chafee, Z., Jr. (1932). Bills of peace with multiple parties. Harvard Law Review, 45, 1297-1332.

Chafee, Z., Jr. (1950). Some Problems of Equity. Ann Arbor, MI: University of Michigan Law School.

Che, Y.-K. (1996). Equilibrium formation of class action suits. Journal of Public Economics, 62, $339-361$.

Che, Y.-K. (2002). The economics of collective negotiation in pre-trial bargaining. International Economic Review, 43, 549-575.

Coffee, J. C., Jr. (1987). The regulation of entrepreneurial litigation: Balancing fairness and efficiency in the large class action. University of Chicago Law Review, 54, 877-937.

Coffee, J. C., Jr. (1995). Class wars: The dilemma of the mass tort class action. Columbia Law Review, 95, 1343-1465.

Coffee, J. C., Jr. (1998). Conflicts, consent, and allocation after Amchem Products - Or, why attorneys still need consent to give away their clients' money. Virginia Law Review, 84, 1541-1559.

Dana, D. A. (2006). Adequacy of representation after Stephenson: A Rawlsian/behavioral economics approach to class action settlements. Emory Law Journal, 55, 279-346.

d'Aspremont, C., Jacquemin, A., Gabszewicz, J. J., \& Weymark, J. A. (1983). On the stability of collusive price leadership. Canadian Journal of Economics, 16, 17-25.

Deffains, B. \& Langlais, E. (2011). Informational externalities and settlements in mass tort litigations. European Journal of Law and Economics, 32, 241-262. 
Deffains, B. \& Langlais, E. (2012). A case for information sharing in class action suits. In J. G. Backhaus, A. Cassone, \& G. B. Ramello (Eds.), The Law and Economics of Class Actions in Europe: Lessons from America. Cheltenham, UK: Edward Elgar, Chap. 10.

Edelman, P. H., Nagareda, R. A., \& Silver, C. (2006). The allocation problem in multiple-claimant representations. Supreme Court Economic Review, 14, 95-112.

Eisenberg, T. \& Miller, G. P. (2004). The role of opt-outs and objectors in class action litigation: Theoretical and empirical issues. Vanderbilt Law Review, 57, 1529-1567.

Gould, J. P. (1973). The economics of legal conflicts. Journal of Legal Studies, 2, 279-300.

Hay, B. \& Rosenberg, D. (2000). "Sweetheart" and "blackmail" settlements in class actions: Reality and remedy. Notre Dame Law Review, 75, 1377-1408.

Hensler, D. R. (2001). Revisiting the monster: New myths and realities of class action and other large scale litigation. Duke Journal of Comparative and International Law, 11, 179-213.

Hensler, D. R., Pace, N. M., Dombey-Moore, B., Giddens, B., Gross, J., \& Moller, E. K. (2000). Class Action Dilemmas: Pursuing Public Goals for Private Gain. Santa Monica, CA: RAND Corporation.

Hylton, K. N. (1993). Litigation cost allocation rules and compliance with the negligence standard. Journal of Legal Studies, 22, 457-476.

Hylton, K. N. (2006). Information, litigation, and common law evolution. American Law and Economics Review, 8, 33-61.

Kane, M. K. (2018). Federal rules of civil procedure. In A. Wright, A. R. Miller, M. K. Kanea, R. L. Marcus, A. B. Spencer, \& A. N. Steinman (Eds.), Federal Practice and Procedure, Volume 7AA, Third Edition. St. Paul, MN: West.

Kaplow, L. \& Shavell, S. (2002). Fairness versus Welfare. Cambridge, MA: Harvard University Press.

Kishinevsky, R. (2017). Damage averaging - how the system harms high-value claims. Texas Law Review, 95, 1145-1163.

Klonoff, R. H. (2013). The decline of class actions. Washinton University Law Review, 90, 729-838.

Klonoff, R. H. (2017). Class actions part II: A respite from the decline. New York University Law Review, 92, 971-997.

Konishi, H., Le Breton, M., \& Weber, S. (1997). Group formation in games without spillovers. In C. Carraro \& D. Siniscalco (Eds.), New Directions in the Economic Theory of the Environment. Cambridge: Cambridge University Press, 281-310. 
Kornhauser, L. A. (1983). Control of conflicts in class-action suits. Public Choice, 41, 145-175.

Kornhauser, L. A. (1998). Fair division of settlements: A comment on Silver and Baker. Virginia Law Review, 84, 1561-1580.

Landes, W. M. (1971). An economic analysis of the courts. Journal of Law and Economics, 14, 61-107.

Macey, J. R. \& Miller, G. P. (1991). The plaintiffs' attorney's role in class action and derivative litigation: Economic analysis and recommendations for reform. University of Chicago Law Review, $58,1-118$.

Macey, J. R. \& Miller, G. P. (2009). Judicial review of class action settlements. Journal of Legal Analysis, 1, 167-205.

Marceau, N. \& Mongrain, S. (2003). Damage averaging and the formation of class action suits. International Review of Law and Economics, 23, 63-74.

Miller, A. (1979). Of Frankenstein monsters and shining knights: Myth, reality, and the "class action problem". Harvard Law Review, 92, 664-694.

Miller, A. R. (2018). The american class action: From birth to maturity. Theoretical Inquiries in Law, 19, 1-45.

Morawetz, N. (1993). Bargaining, class representation, and fairness. Ohio State Law Journal, 54 , $1-65$.

Mullenix, L. S. (1986). Class resolution of the mass-tort case: A proposed federal procedure act. Texas Law Review, 64, 1039-1099.

Mullenix, L. S. (1991). Beyond consolidation: Postaggregative procedure in asbestos mass tort litigation. William and Mary Law Review, 32, 475-585.

Nagareda, R. A. (2002). Autonomy, peace, and put options in the mass tort class action. Harvard Law Review, 115, 747-830.

Nagareda, R. A. (2003). Closure in damage class settlements: The Godfather guide to opt-out rights. University of Chicago Legal Forum, 2003, 141-175.

Okun, A. M. (1975). Equality and Efficiency: The Big Tradeoff. Washington, DC: Brookings Institution Press.

Perino, M. A. (1997). Class action chaos: The theory of the core and an analysis of opt-out rights in mass tort class actions. Emory Law Journal, 46, 85-161.

Posner, R. A. (1973). An economic approach to legal procedure and judicial administration. Journal of Legal Studies, 2, 399-459. 
Priest, G. L. \& Klein, B. (1984). The selection of disputes for litigation. Journal of Legal Studies, $13,1-55$.

Ratner, M. A. (2017). Class conflicts. Washington Law Review, 92, 785-860.

Rave, D. T. (2013). Governing the anticommons in aggregate litigation. Vanderbilt Law Review, $66,1183-1258$.

Rosenberg, D. (2002). Mandatory-litigation class actions: The only option for mass tort cases. Harvard Law Review, 115, 831-897.

Rosenberg, D. (2003). Adding a second opt-out to rule 23(b)(3) class actions: Cost without benefit. University of Chicago Legal Forum, 2003, 19-69.

Rutherglen, G. (1996). Better late than never: Notice and opt out at the settlement stage of class actions. New York University Law Review, 71, 258-295.

Schuck, P. H. (1995). Mass torts: An institutional evolutionist perspective. Cornell Law Review, 80, 941-989.

Shapiro, D. L. (1998). Class actions: The class as party and client. Notre Dame Law Review, 73, 913-961.

Shavell, S. (1982). Suit, settlement, and trial: A theoretical analysis under alternative methods for the allocation of legal costs. Journal of Legal Studies, 11, 55-81.

Silver, C. (2000). Class actions - representative proceedings. In B. Bouckaert \& G. De Geest (Eds.), Encyclopedia of Law and Economics, Volume V. Cheltenham, UK: Edward Elgar, 194-240.

Silver, C. \& Baker, L. A. (1998). I cut, you choose: The role of plaintiffs' counsel in allocating settlement proceeds. Viriginia Law Review, 84, 1465-1540.

Weikard, H.-P. (2009). Cartel stability under an optimal sharing rule. Manchester School, 77, 575593.

Weinstein, J. B. (1995). Individual Justice in Mass Tort Litigation: The Effect of Class Actions, Consolidations, and Other Multiparty Devices. Evanston, IL: Northwestern University Press.

Williams, R. C. (2015). Due process, class action opt outs, and the right not to sue. Columbia Law Review, 115, 599-659.

Yeazell, S. C. (1987). From Medeival Group Litigation to the Modern Class Action. New Haven, CT: Yale University Press.

Yi, S.-S. (2003). Endogenous formation of economic coalitions: A survey of the partition function approach. In C. Carraro (Ed.), The Endogenous Formation of Economic Coalitions. Cheltenham, UK: Edward Elgar, 80-127. 